\title{
The role of emotional intelligence on coach-athlete relationships and motivational climate
}

\author{
Eric E. Steege \\ West Virginia University
}

Follow this and additional works at: https://researchrepository.wvu.edu/etd

\section{Recommended Citation}

Steege, Eric E., "The role of emotional intelligence on coach-athlete relationships and motivational climate" (2009). Graduate Theses, Dissertations, and Problem Reports. 4538.

https://researchrepository.wvu.edu/etd/4538

This Thesis is protected by copyright and/or related rights. It has been brought to you by the The Research Repository @ WVU with permission from the rights-holder(s). You are free to use this Thesis in any way that is permitted by the copyright and related rights legislation that applies to your use. For other uses you must obtain permission from the rights-holder(s) directly, unless additional rights are indicated by a Creative Commons license in the record and/ or on the work itself. This Thesis has been accepted for inclusion in WVU Graduate Theses, Dissertations, and Problem Reports collection by an authorized administrator of The Research Repository @ WVU. For more information, please contact researchrepository@mail.wvu.edu. 
The Role of Emotional Intelligence on Coach-Athlete Relationships and Motivational Climate

Eric E. Steege, B.A.

\author{
Thesis submitted to the \\ College of Physical Activity and Sport Sciences \\ at West Virginia University \\ in partial fulfillment of the requirements for the degree of
}

Master of Science

In

Physical Education with an emphasis in

Sport and Exercise Psychology

Samuel Zizzi, Ed.D., Chair

Kristen Dieffenbach, Ph.D.

Roy Tunick, Ed.D.

Sport and Exercise Psychology Program

Morgantown, West Virginia

2009

Keywords: Coaching, Sports, Emotion, Motivation, Social Skills 


\begin{abstract}
The Role of Emotional Intelligence on Coach-Athlete Relationships and Motivational Climate
\end{abstract}

\title{
Eric Steege
}

Research has revealed that Emotional Intelligence is linked to improved conflict resolution, enhanced social attachments and mental health, and the ability to create a collective set of goals that motivate others (Pau \& Croucher, 2003). The recent surge of research assessing the role EI may play in leadership effectiveness, motivation, and social attachments within nonsport domains overlaps with similar research within sport that assesses the influence of emotion on coaching effectiveness (Frijda \& Mesquita, 1994; Mageau \& Vallerand, 2003). Thus, the purpose of this investigation was to examine if higher EI coached athletes $(\mathrm{N}=34)$ varied compared to lower EI coached athletes $(\mathrm{N}=46)$ in their strength of the coach-athlete relationship, perceived motivational climate, college soccer satisfaction, and coaches' ability to motivate. Results of the investigation indicate that lower EI coached athletes reported stronger coachathlete relationships compared to higher EI coached athletes but no significant difference between the groups were reported on perceived motivational climate, college soccer satisfaction, and coaches' ability to motivate. The practical implications of these results are discussed, while relevant EI research within non-sport domains and a purposed line of coaching research using EI theory are explored. 


\section{DEDICATION}

To my mother and father -

Thank you for your unconditional love, and teaching me the value of hard work and self-belief. You are great role models and I aspire to live life like you on a daily basis.

To my sister -

Your compassionate, non-judgmental approach to life continues to motivate to be a better a person.

I love you Mom, Dad, and Julia 


\section{ACKNOWLEDGMENTS}

There have been many people that have collaborated and contributed to the process and completion of this thesis. Thus, there are many people that I would like to acknowledge that have helped me along the way.

I would first like to thank my advisor and committee chair, Dr. Sam Zizzi. Thank you for sharing your knowledge and for always making yourself available to meet and discuss this project. Your work providing feedback on many drafts helped this manuscript reach its full potential. I appreciated the patience and your good use of "emotional intelligence" to help me stay motivated from start to finish.

I would like to thank Dr. Kristen Dieffenbach for the role she has played in this process. I would like to express my appreciation for the time she dedicated especially in the initial methods design phase.

A special thanks to Dr. Roy Tunick for his great comments and feedback during the thesis proposal stage.

Lastly, thanks to all the soccer coaches and players for the cooperation and participation. Without your willingness to participate, this research would not have come to fruition. Thank you. 


\section{TABLE OF CONTENTS}

pg. \#



Emotional Intelligence Research Outside of Sport......................................................... 2

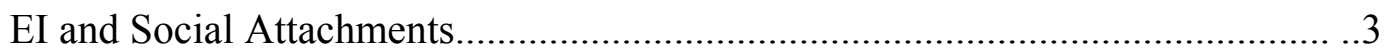

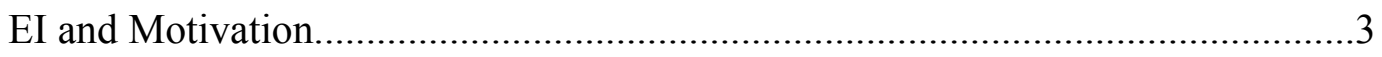

EI Research with Athletes and Coaches..................................................................... 4

EI's Influence on Social Attachments. ...............................................................

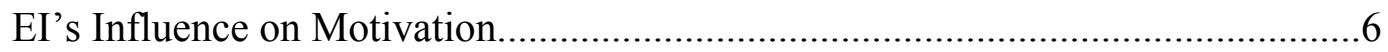

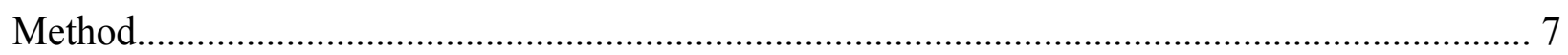

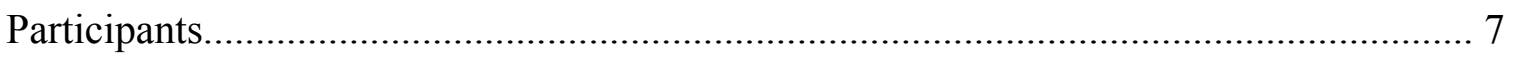

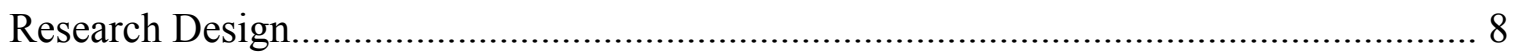

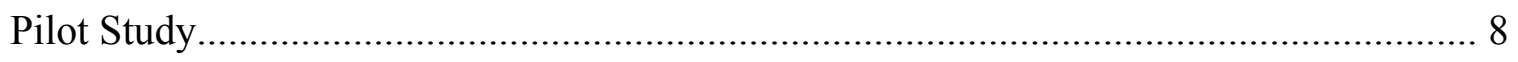

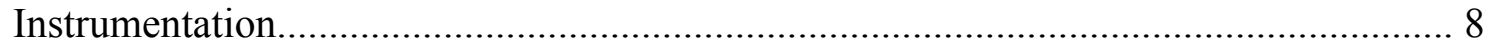

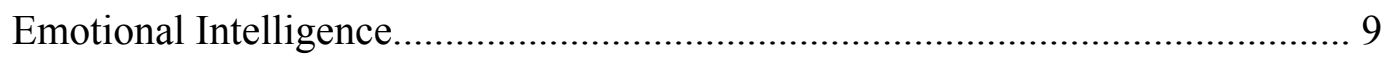

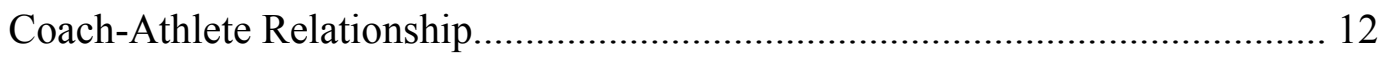

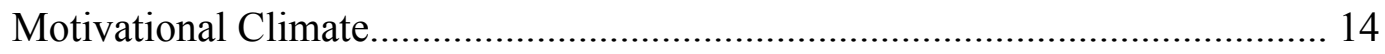

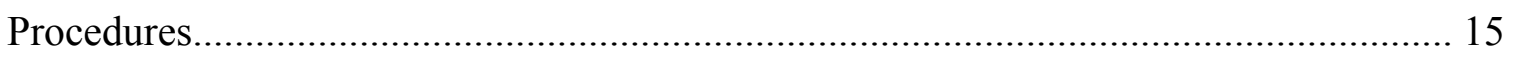



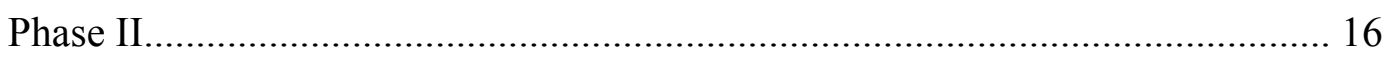

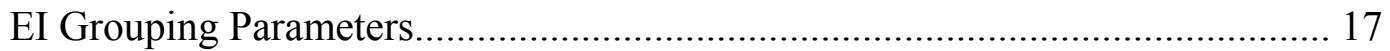

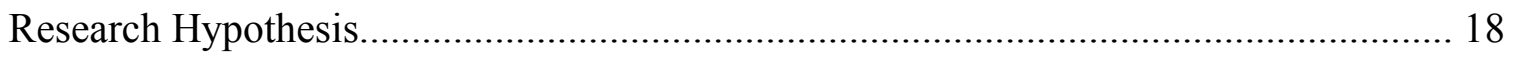

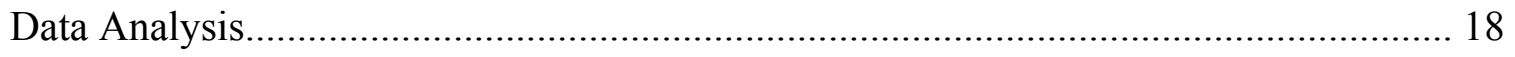

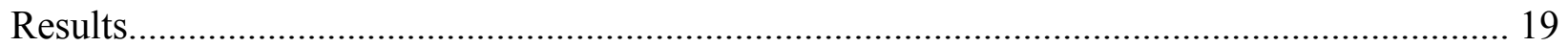


Descriptive Statistics of Phase I Athletes and Coaches............................................ 19

Correlations with Athlete CART-Q and PMCSQ-2 Scores.......................................... 20

Correlations with Coach MSCEIT Scores.................................................. 21

Independent T-Test Between EI Groups................................................... 21

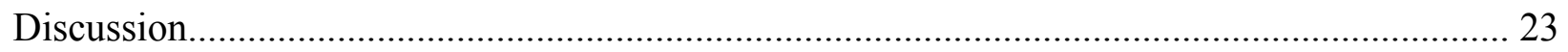

Differences Between Higher EI Coached Athletes and Lower EI Coached Athletes...... 23

Correlation Results.................................................................................. 26

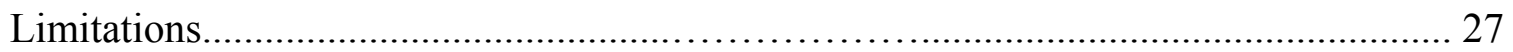





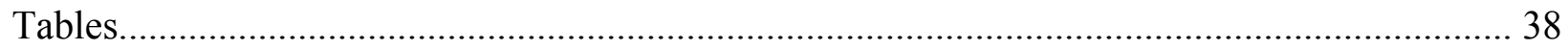

Table 1- Descriptive Data for Coaches................................................................. 38

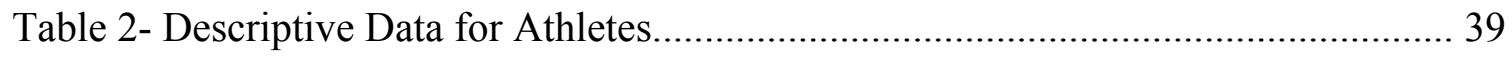

Table 3- Correlations with Athlete CART-Q and PMCSQ-2 ................................... 40

Table 4- Correlations with Coach EI Score............................................... 41

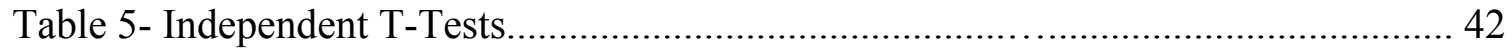

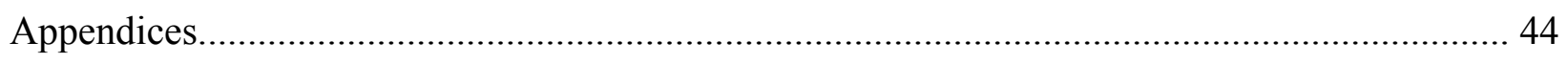

APPENDIX A Coach Demographic Questionnaire.................................................... 44

APPENDIX B Coach Perception of Coach-Athlete Relationship Measure.................. 47

APPENDIX C Athlete Demographic Questionnaire.............................................. 49

APPENDIX D Meyer-Salovey-Caruso Emotional Intelligence Test............................ 52

APPENDIX E Coach-Athlete Relationship Questionnaire...................................... 54

APPENDIX F Perception of Motivational Climate in Sport Questionnaire-2.................56 
APPENDIX G Statement of the Research Problem..................................................60

APPENDIX H Review of Literature. 66

APPENDIX I Review of Literature References...................................................... 102 


\section{Introduction}

What does it take to be a successful coach? While coaches flock to workshops to listen to championship coaches analyze film and explain their latest tactical philosophy, most elite coaches admit that there are other critical skills beside just tactical knowledge that are at the root of their success. These elite coaches know that X's and O's are important; however, they insist that their success hinges on their ability to connect to and motivate their athletes (Clews \& Gross, 1995; Janssen \& Dale, 2002; Weiss \& Ferrer-Caja, 2002). Vince Lombardi, the former Green Bay Packer Hall of Fame coach lamented "coaches who can outline plays on a black board are a dime a dozen. The ones who win get inside their players' heads and motivate" (Janssen \& Dale, 2002, p. 9). Research specific to sport coaching has proposed that it takes more than just technical knowledge for a coach to positively affect performance of teams and individual athletes (Clews \& Gross, 1995; Hoigaard \& Jorgensen, 2007; Janssen \& Dale, 2002).

Research within the field of sport psychology indicates emotions from coaches and teammates play a vital part in team development and performance (Botterill \& Brown, 2002; Jones, 2003; Jones \& Swain, 1995; Lazarus, 2000). The majority of emotion research within the sport domain has focused on the use of psychological skills by athletes to control negative emotions such as anxiety, anger, and fear of failure in an attempt to more consistently achieve peak performances. Several specific psychological skills, including emotional awareness and emotion regulation, have been found to play critical roles in positively affecting athletic performance for teams and individual athletes (Hanin, 2000; Jones, 2003; Mageau \& Vallerand, 2003; Ravizza, 2006; Vallerand \& Blanchard, 2000). The abilities to possess emotional awareness and appropriately regulate emotions are non-general intelligence skills that have been conceptualized into the construct of emotional intelligence (Salovey \& Mayer, 1990). 
The core concepts of emotional intelligence (e.g. emotional awareness and regulation) and how they affect social interactions and achievement are not new. Many individuals have discussed such topics for centuries as evident by Aristotle's quotation, “Anyone can be angry that is easy. But to be angry with the right person, to the right degree, at the right time, for the right purpose, and in the right way - that is not easy" (as cited in Goleman, 2002, p. 80). Modern day research has also suggested that recognizing and appropriately responding to follower's emotions is necessary for leaders to develop high quality interpersonal relationships (Salovey \& Mayer, 1990). Emotional intelligence has been defined by Mayer and Salovey (1990) as a:

...set of skills hypothesized to contribute to the accurate appraisal and expression of emotion in oneself and in others, the effective regulation of emotion in self and others and the use of feelings to motivate, plan and achieve in one's life. (p. 185)

\section{Emotional Intelligence Research Outside of Sport}

In the two decades following Salovey and Mayer's seminal work defining the term "emotional intelligence" (EI) and establishing the Mayer-Salovey-Caruso Emotional Intelligence Test (MSCEIT), the concept of EI has burgeoned into a popular line of research within the domains of business, health-care, and other fields in which human interactions are critical to performance. Many occupational fields have begun to incorporate EI into employee training programs including mental and physical health care (Evans \& Allen, 2002) and corporate management (George, 2000) as an attempt to develop employees with better interpersonal skills. EI measures have been integrated into the job hiring process to aid with evaluating and selecting 
applicants. For example, an EI measure was included as part of a medical school application process at an esteemed university medical school (Elam, 2000) because caring and compassion are central tenants of EI and influence the quality of the doctor-patient relationship. Integrating an EI component into training employee workshops and the job hiring process is evidence that the medical and corporate fields believe that performance is not only predicated by intelligence scores and technical abilities, but also by emotional abilities.

A study using dental school students revealed that high EI is related to optimism, improved mood regulation, and increased coping skills (Pau \& Croucher, 2003). These skills could be important for dental/medical facilities to considering when hiring new employees because optimism, improved mood regulation, and increased coping skills may allow healthcare professionals to better cope with stress in the work place without job performance suffering. Research also indicates that EI is linked to improved conflict resolution, enhanced social attachments and mental health (Fullam, 2002), and the ability to create a collective set of goals that motivate others. Thus, proponents suggest EI may play an integral role in developing social attachments, motivating others, and ultimately leadership effectiveness in corporate and medical healthcare fields (Allen \& Cohen, 2006; George, 2000).

EI and Social Attachments. Emotional intelligence has been positively correlated with empathy (i.e., perceived emotional response to others and concerned about the feeling of others) (Mayer, Caruso, \& Salovey, 1999). EI influences a leader's ability to effectively teach in a caring manner and coaching, after all, is about teaching (Magyar et al., 2007). Thus, the strength of a relationship between a leader and follower could be dependent on a leader's EI. In addition, because emotional intelligence may influence the quality of interpersonal relationships between a 
leader and a follower (Mageau \& Vallerand, 2003), EI may influence how well a leader can motivate followers.

EI and Motivation. Effectively using emotions may allow a leader to take into account multiple view points when problem-solving so as to facilitate creative and sensitive solutions that take into account a follower's best interest (George, 2000). In addition, leaders who effectively use emotions can generate enthusiasm for projects and provide motivation and direction to groups and themselves (Palmer et al., 2002). As Barach and Eckhardt suggested (1996, p.4) "leadership which embraces the emotional side of directing organizations pumps life and meaning into management structures, bringing them to full life". Thus, since an important component of leadership seems to be the effective use of emotions, emotional intelligence may play an important role in motivation and leadership.

Effective leaders need to be able to distinguish between genuine and fake emotions. For example, when enthusiasm is faked, a leader needs to be able to sense this, and determine why the enthusiasm is not genuine. A leader high in EI should have the ability to appraise other people's emotions, label and understand those emotions, and manage their own emotions.

Interestingly, research has shown that people often strategically control their expressed emotions (Ekman, 1973). Thus, EI may allow leaders the ability to better understand what motivations are behind individuals expressed emotions and, in turn, be better equipped to motivate. In addition, because EI may allow leaders to build intrinsic motivation, there may be a link to the perceived motivational climate (e.g. mastery versus performance) within groups of followers (Palmer, et al., 2002). Taken together, Caruso and colleagues (2004) suggest EI may be closely linked to an individual's ability to establish productive motivational climates and lead followers. 
Emotion has long been established as producing a critical influence on interpersonal relationships (Darwin, 2005). Emotions are recognized by others, they shed light upon the emotional relevance of the environment, they exert an influence on social events, they affect interpersonal relationships, and they evoke reciprocal responses from others that further affect relationships (Frijda \& Mesquita, 1994). For example, simply observing a coach smile may cause players to smile and feel happier and more at ease. Thus, there is a tendency to "catch" another person's expressed emotion. However, the ability to accurately appraise and express emotions is required for this process to occur. With this argument in mind, one could predicate that coaches high in EI could recognize when their team needs a positive pick-me-up and have the ability to regulate and then appropriately express their emotions with the desired positive facial expression. Alternatively, a coach low in EI may fail to ever recognize that his/her team is in a fragile emotional state, and never think to strategically express positive emotions in an attempt to calm or raise the spirit of the team. Thus, research on EI in sport coaching could provide valuable insight into how this process occurs.

To date, several published theoretical papers draw parallels between leadership effectiveness in business and sport (Jones, 2002; Weinberg \& McDermott, 2002) as well as hypothesize that EI may be an important paradigm within the sport domain (Botterill \& Brown, 2002; McCann, 1999; Meyer \& Fletcher, 2007; Zizzi, Deaner, \& Hirschhorn, 2003). The aforementioned researchers suggest, given the role a leader's EI plays in well-being, satisfaction, and performance within corporate and healthcare fields, it would seem logical that these research findings would be consistent in leadership in sport.

EI's Influence on Social Attachments. Researchers have expressed a growing interest in the coach-athlete relationship (Jowett \& Poczwardowski, 2007; Mageau \& Vallerand, 2003). 
Mutual trust, respect, and support are coaching qualities that contribute to satisfying and successful coach-athlete relationships (Jowett, 2007; Jowett \& Cockerill, 2003; Poczwardowski, Barott, \& Peregoy, 2002). In fact, numerous coach-athlete theories have been established including the 3 C's model (Jowett \& Ntoumanis, 2004) of closeness, commitment, and complementarity that is used in this study. Interestingly, such coach-athlete theory research suggests that emotions, when properly managed and expressed, can drive trust, loyalty, and commitment (Fullam, 2002; Jowett \& Ntoumanis, 2004; Palmer et al., 2000). Thus, emotional awareness in self and others coupled with sensitivity (emotional regulation) in communication could play an important role in forming positive social relationships between teammates and coaches.

EI's Influence on Motivation. Surveys of athlete motivation have identified coaching behaviors as a major factor in determining whether athletes choose to continue or drop out of sport (Lee, 1999; Weiss \& Ferrer-Caja, 2002). Specifically, Weiss and Ferrer-Caja (2002) in their study on motivational orientations and sport behavior, suggested that the ways in which coaches emotionally respond to athletes can significantly affect their athletes' perceived competence, global self-worth, affect, motivational orientation, and actual participation. Thus, it is possible that coaches higher in EI will help athletes feel more competent and motivated during their sport experiences, which could lead to continued participation. In addition, providing choice and building competence in young sport participants has been linked to increased intrinsic motivation, which is posited to lead to increased effort, enjoyment, and persistence in sport and other physical activities (Brustrad, 1988, Wankel \& Kreisel, 1985).

There is substantial research within the sport domain to support the positive impact of mastery-based motivational climates on favorable attitudes toward winning (Ntoumanis \& 
Biddle, 1999), quality of relationship with teammates and coaches (Fry \& Newton, 2003), skill development (Theeboom et al., 1995), and perceived improvement, satisfaction with instruction, degree of preference for the coach (Balaguer, Duda \& Crespo, 1996). However, to date, only one peer-reviewed research article has examined the relationship between emotional intelligence and coaching efficacy (Thelwell, Lane, Weston, \& Greenlees, 2008). Further research is needed to understand the potential use of EI in coaching education and performance, and how EI relates to previously established coaching factors such as the coach-athlete relationship and motivational climate.

\section{Method}

The purpose of this research investigation is to examine the relationships between a coach's level of emotional intelligence, the coach-athlete relationships, and the motivational climate of a team. The ultimate goal is to better understand differences between coaches higher in EI compared with coaches who are lower in EI in their ability to connect to and motivate athletes. The methods described in this chapter will be organized into the following sections: (1) participants; (2) research design; (3) pilot research; (4) instrumentation; (5) procedures; (6) hypotheses; and (7) data analyses.

\section{Participants}

A total of 232 athletes and 98 coaches and then subset of 81 athletes (from 7 different teams) and 7 coaches participated in this research investigation. Coaches and players were all male and recruited nationally from DIII NCAA soccer teams. Participants were contacted via email. Approval from the Institutional Review Board for the Protection of Human Subjects was obtained prior to the collection of data. Due to the nature of sampling of coaches and athletes, the investigator knows the identities of the participants. However, all identifying information 
was removed when the results are compiled for analysis and participants were identified only by coded numbers on all questionnaires and assessment data.

\section{Research Design}

This study employed a correlational, descriptive design. The independent variable in this study was the emotional intelligence level of an athlete's coach as measured by the online version of the Mayer-Salovey-Caruso Emotional Intelligence Test (MSCEIT). Dependent variables include: (1) coach - athlete relationship assessed using the Coach-Athlete Relationship Questionnaire (CART-Q; Appendix E; Jowett \& Ntoumanis, 2004); (2) athletes' perceived motivational climate assessed using Perceived Motivational Climate in Sport Questionnaire-2 (PMCSQ-2; Appendix F; Newton et al., 2000); (3) athlete's perception of coach's ability to motivate players assessed using the athlete demographic questionnaire (see Appendix C); and (4) athlete's sport participation satisfaction assessed using the athlete demographic questionnaire.

\section{Pilot Study}

100 DIII NCAA head men's soccer coaches were contacted as part of a pilot study via email to gauge potential interest to participate in this study. Twenty-six out of the 100 coaches responded and out of the twenty-six coaches that responded, twenty-two said they would be interested in participating while also indicating interest in providing access to their team to participate in this study. This provides evidence that recruiting an adequate coaching and athlete sample size for this current study was likely.

\section{Instrumentation}

A demographic questionnaire (See Appendix A) was administered to each coach. The questionnaire contained information regarding age, education, number of years as a head college soccer coach, number of years coaching this specific team, career college head coach win-loss 
record, and this specific team's conference winning percentage the last four years. Each coach was asked to rate how effective they feel they are at building a positive relationship with their players, knowing how to motivate their players, and being 'in tune' with their athletes' emotions on single items using a 5-point scale ( $1=$ Very Ineffective to $5=$ Very Effective). Lastly, Phase I coaches were asked to rate the quality of their relationship with each player on their team on single items using a 5 point scale (See Appendix B; $1=$ extremely bad to $5=$ extremely good).

In Phase II, a demographic questionnaire (See Appendix C) was administered to each player. The questionnaire contained information regarding age, year in school, years on team, college career games played and games started. Lastly, each athlete was asked to rate how effective their coach is at building a positive relationship with them, knowing how to motivate them, and being 'in tune' with their motivations on single items using a 5-point scale $(1=$ very ineffective to $5=$ very effective).

Emotional Intelligence. The level of current emotional intelligence of coaches was assessed using the Mayer-Salovey-Caruso Emotional Intelligence Test (MSCEIT; Mayer, Salovey, \& Caruso, 2002; see Appendix D). The MSCEIT is a test of emotional intelligence designed for adults ages 17 years and older. The MSCEIT assesses the four branch ability model of EI (perceiving, using, understanding, and regulating emotions) with 141-items, that are divided among eight tasks (two for each branch). The test provides seven scores: one for each of the four branches, two area scores, and a total EI score. The two area scores are termed Experiential EI (branches 1 and 2 combined) and Strategic EI (branches 3 and 4 combined). In order to be scored, each completed MSCEIT needs to be submitted to the test manufacturer. The test manufacturer uses two scoring systems: a consensus score based upon the agreement of a large number of people who have taken the test previously and an expert score based upon the 
agreement of a panel of experts. Given the nature of emotional information, there is adequate justification for both a general consensus scoring method as well as an expert method. Over time, however, it is likely that the MSCEIT will move to a single scoring method. Thus, the only score that that will be used to assess the EI of coaches will be consensus scores.

The first branch of EI, emotional perception (EP), is measured by a faces task (participants identify emotions depicted in faces) and a pictures task (participants label emotions represented in landscapes or art). Emotion terms (e.g., happiness, fear, surprise, disgust, and excitement $)$ are rated on 5 -point scales $(1=$ none, $5=$ extreme $)(\alpha=.91)$. For example, in the faces task, participants are presented with a picture of a person expressing a basic emotion. Below the picture is a list of five emotions; the subject is asked to rate on a five-point scale how much of a particular emotion is expressed in the picture.

The second branch of EI, emotional integration to facilitate cognition (FC), is measured by a synesthesia task (participants compare emotions to sensations) and an acilitation task (participants rate the usefulness of specific emotions in different situations). Emotions are rated on 5 -point scales $(1=$ not alike, $5=$ very much alike; $1=$ definitely not useful, $5=$ definitely useful, respectively) $(\alpha=.90)$. For example, a question on the synesthesia task presents participants with a sentence asking them to imagine feeling an emotion such as shame. Participants are then given a list of adjectives pertaining to other sensory adjectives (e.g., cold, blue, and sweet) and are asked to rate on a five-point scale how much the feeling of shame is similar to the adjectives.

The third branch of EI, emotional understanding (EU), is measured by a blends task (participants analyze blended/complex emotions) and a changes task (participants analyze how emotional reactions change over time or how they follow upon one another) $(\alpha=.77)$. For 
example, a question on the blends task presents statements such as "Acceptance, joy, and warmth often combine to form..." Participants are then presented with a list of response alternatives and choose the most appropriate.

The fourth branch of EI, emotional management (EM), has two subsets that assess how participants manage emotions of others (social management), and how a person would regulate his or her own emotions (emotional management). For example, participants read a story and answer questions about how a person's actions in that story affect (a) that character's emotions or (b) the emotions of other characters in the story $(\alpha=.87)$. All $\alpha$ 's $(N>5000)$ above were obtained from the MSCEIT test manual (Mayer et al., 2002).

Normative data are from a sample of over 5,000 individuals. MSCEIT scores are standardized to $M=100$ and $S D=15$ (Mayer et al., 2002). The two area scores (Experiential and Strategic EI) reliabilities are .90 and .90 . The test-retest reliability over a three-week interval with $N=63$ was $r(59)=.86, p<.001$ (Brackett \& Mayer, 2003). In addition, the MSCEIT appears to show appropriate discriminant validity from measures of analytic intelligence and many personality constructs (Brackett \& Salovey, 2006; Mayer et al., 2003).

Since MSCEIT scores have little variance that overlaps with personality measures this suggests, EI as measured by the MSCEIT, seems to be an independent intelligence distinct from personality traits. This is important because this provides supports to the ability model definition of EI that posit EI is an ability that can be learned/improved and not a personality trait that someone is born with.

Scores for participants was obtained from the test publisher. Consensus EI scores was calculated for each branch and averaged for one overall consensus EI score. Please see 
Procedure section to see how the coach MSCEIT scores were used to place athletes into the "High EI coached athletes" or "Low EI coached athletes" groups.

Coach-Athlete Relationship. The level of the coach-athlete relationship was assessed among soccer athletes using the Coach-Athlete Relationship Questionnaire (CART-Q; Jowett \& Ntoumanis, 2004; see Appendix E). This measure is grounded in previous qualitative work, as well as in interpersonal relationship and behavior literature. Qualitative work done by Jowett and Meek (2000) supported the existence of Closeness, Co-orientation, and Complementarity as three main constructs that influence the coach-athlete relationship. However, item and factor analyses failed to support the construct of Co-orientation, but also revealed the emergence of the construct of Commitment (Jowett \& Ntoumanis, 2004). The conceptualization of the coachathlete relationship model was reflected in the CART-Q by including subscales for the 3 main “C”'s of Closeness (emotions), Commitment (cognitions), and Complementarity (behaviors).

Within Jowett's construct of the coach-athlete relationship and the CART-Q, the athletes' and coaches' closeness, commitment, and complementarity can be measured from a direct and/or meta-perspective. The direct perspective assess either the athlete's or coach's perception of closeness, commitment, and complementarity relevant to the other member, whereas the metaperspective assesses the degree to which an athlete or coach can accurately predict the other member's closeness, commitment, and complementarity. Thus, Jowett developed two variations of the CART-Q, a direct and meta-perceptive variation each with an athlete and coach version (each version has similar 11 items). The direct perspective measures an athlete's or coach's perceptions of the 3 main "C"s in the relationship. Directions for the coach version for the direct perspective measure are "Please respond to the statements as honest as possible and relevant to how you personally and generally feel with a specific athlete from your team or squad." The 
meta-perspective measures an athlete's or coach's inference about how the other member feels about the 3 main "C"s in the relationship. Directions for the athlete version for the metaperspective measure are "Please respond to the statements as honest as possible and relevant to how you personally think your coach feels about you." Participants respond on a 7-point Likerttype scale ranging from "Strongly Agree" to "Strongly Disagree." The CART-Q measures the intensity of a coach's and athlete's levels of Closeness (e.g., "if I respect my coach"), Commitment (e.g., "I am committed to my coach") and Complementarity (e.g., "When I coach my athlete, I am responsive"). The subscales scores for each of the 3 C's and the overall score was evaluated in the CART-Q.

The CART-Q has been found to be both reliable and valid for assessing both coach perceptions and athlete perceptions of the coach-athlete relationship dyad (Jowett \& Ntoumanis, 2004). Using a sample of 120 British study participants, of which 50\% were coaches and 50\% were athletes, validity for the CART-Q was determined by correlating the variable of interpersonal satisfaction with the three derived constructs with a satisfactory internal consistency $(\alpha=0.83)$. Pearson's correlation coefficients indicated positive and moderately high relationships between the variable of interpersonal satisfaction and Closeness $(\mathrm{r}=0.75 ; p<0.01)$, Commitment $(r=.62 ; p<0.01)$, and Complementarity $(r=0.59 ; p<0.01)$. These results lend support to the validity of the CART-Q (Jowett \& Ntoumanis, 2004).

In addition to examining the validity of the questionnaire, the internal consistency of each of the CART-Q subscales was assessed using a sample of 214 British study participants, of which $35 \%$ were coaches and $65 \%$ were athletes. Cronbach's $\alpha$ coefficients were $\alpha=0.82$ for Commitment, $\alpha=0.87$ for Closeness, and $\alpha=0.88$ for Complementarity. The $\alpha$ for the higherorder Coach-Athlete Relationship scale was 0.93 (Jowett \& Ntoumanis, 2004). In the current 
sample, these items show good internal consistency on Closeness $(\alpha=.874)$ and

Complementarity $(\alpha=.775)$ but only adequate internal consistency on Commitment $(\alpha=.622)$.

It is important to note that even though this measure has good psychometrics properties, it is relatively new and has been used by few researchers outside of Jowett and her colleagues. However, the CART-Q is the best measure of the coach-athlete relationship for this study's specific focus for the following reasons. First, as alluded to in the coach-athlete relationship section of the literature review (see Appendix I), measuring the coach-athlete relationship using a direct perspective version (emotional awareness in self) and a meta-perspective version (emotional awareness in others), as the CART-Q does, aligns with important constructs of EI theory. In addition, the CART-Q is significantly shorter than any another other reliable and validated measure of coach-athlete relationship and this provides a major advantage when collecting self-report data with athletic teams.

Motivational Climate. Team climate was assessed using the Perceived Motivational Climate in Sport Questionnaire-2 (PMCSQ-2; Newton et al., 2000; see Appendix F) and is based on seminal goal orientation theory research (Newton et al., 2000; Nicholls, 1989). The PMCSQ2 is a 33-item self-report questionnaire with items representing two higher-order climates: TaskInvolving (i.e. mastery; 17 items) and Ego-Involving (i.e. performance; 16 items) climates. Each higher-order climate has three subscales: Task-involving climate with subscales of Cooperative Learning, Effort/ Improvement, Important Role and Ego-involving climate with subscales of Intra-Team Member Rivalry, Unequal Recognition, and Punishment for Mistakes. Participants responded to items such as "On this team athletes are encouraged to outdo their own teammates" (Ego-involving climate) or "On this team athletes are encouraged to work on weaknesses" (Taskinvolving climate). Reponses are given on 5-point Likert-type scales $(1=$ strongly disagree, $5=$ 
strongly agree). The test provides one higher-order motivational climate score and scores of each of the 3 subscales. The higher-order motivational climate scores (i.e., Task Involving and EgoInvolving climates scores) will be evaluated in the PMCSQ-2.

Research using the PMCSQ-2 has found adequate internal reliability and factorial validity (Reinboth \& Duda, 2006). Using a sample of 385 adolescent female volleyball players, both scales demonstrated good internal consistency $(\alpha=.87$ for task-involving climate and 0.89 for ego-involving climate; Newton, Duda, \& Yin, 2000). More recent studies have also demonstrated very good internal consistency for the Task-involving and Ego-involving subscales $(\alpha=.91$ and $\alpha=.86$ respectively; Smith et al., 2005). The current sample shows good internal consistency on both Task $(\alpha=.891)$ and Ego $(\alpha=.824)$ subscales.

Convergent validity has been established when examining relationships between the Pressure/Tension subscale of the Intrinsic Motivation Inventory and the Ego-involving climate scale (Newton, Duda, \& Yin, 2000). Because of the adequate validity and reliability scores and common use across numerous sport sub-domains, the PMCSQ-2 has been become an established sport specific measure of perceived motivational climate.

\section{Procedures}

Phase I. Phase I of the study was started at the end of the summer prior to the start of the 2008 fall college soccer season when coaches had more time to complete the demographic questionnaire. In Phase I of the study, 325 NCAA DIII male soccer coaches were contacted via email and sent an introductory letter describing i) the study including indicating the potential of being asked to participate in future phases of the study, ii) precautions that will be taken to assure confidentiality, and iii) directions how to complete and links to an online version of the coach demographic questionnaire (see Appendix A). Specifically, each coach was asked to complete a 
single item measure of their perception of the quality of their coach-athlete relationship with each player on their team including in the coaching demographic questionnaire. Thus, coaches were asked to rate the quality of their relationship for every player on their team on a 5 point scale $(1=$ extremely bad to 5 extremely good $)$.

All participants were informed about the nature of the study and about the voluntary nature of their participation. Receipt of returned questionnaires was taken as informed consent. All documents that contained personal information for study participants was password locked. Three rounds of emails were sent out, one email per week to maximize response rate.

Phase II. Phase II data collection was conducted in the mid October to December $1^{\text {st }}$ to ensure time for new players to get acclimated to their team and to allow collection of more accurate data from players and coaches "in the midst" of the season while limiting recall biasing of data. In Phase II of the study, all of the 98 out of 325 contacted coaches (response rate of $30 \%$ ) that completed the coaching demographic questionnaire were re-contacted via email and sent a letter i) thanking them for the participation in Phase I, ii) notifying them of their selection in Phase II, and iii) describing directions how to complete and links to an online version of the MSCEIT. Again three rounds of emails were sent out, one email per week to maximize response rate and any coach choosing not to participate was advised that there were no penalties for doing so.

From the 98 re-contacted coaches, 28 completed the MSCEIT (response rate of 29\%). Once coaches completed the MSCEIT, it was scored automatically by the test manufacture and test results were provided to the investigator via email in an excel spread sheet.

In addition, all coaches that completed the MSCEIT were asked to send out an email to his players. The text of this email was provided by the investigator and outlined details about the 
study. The email provided an introductory letter to each athlete describing i) the study, ii) precautions that will be taken to assure confidentiality, and iii) directions how to complete and links to an online version of the athlete demographic questionnaire (see Appendix C), an online version of the CART-Q, and an online version of the Perceived Motivational Climate in Sport Questionnaire-2 (PMCSQ-2). All participants were informed about the nature of the study and about the voluntary nature of their participation. Receipt of returned questionnaires was taken as informed consent. Again three rounds of emails were sent out, one email per week to maximize response rate and any athlete choosing not to participate were advised that there were no penalties for doing so.

In total, 232 athletes representing 17 out of the 28 team contacted, completed the questionnaires. All documents that contained personal information for study participants was password locked.

EI Grouping Parameters. MSCEIT scores are based on normative data provided in the MSCEIT manual (Mayer et al., 2002) and are standardized to $M=100$ and $S D=15$. Thus, the original grouping plan was to place athletes into the "High EI coached athletes" group if their coach scored in the upper quartile of the standardized dataset (an EI score in the $75^{\text {th }}$ percentile or higher on the standardized dataset). Athletes will be placed into the "Low EI coached athletes" group if their coach scored in the lower quartile of the standardized data (an EI score in the $25^{\text {th }}$ percentile or lower on the standardized dataset).

However, not enough EI coach scores fell within these criteria to have large enough athlete sample sizes per group. Instead, the groups were established based by the researcher looking at the EI scores on the extreme ends of the coach sample. Specifically, four teams with the highest coach EI scores $(M=108.25 ; \mathrm{SD}=2.16)$ and 3 teams with the lowest coach EI scores 
$(\mathrm{M}=68 ; \mathrm{SD}=4.9)$ with at least $40 \%$ of teammates reporting were used to establish the higher EI coached athletes or lower EI coached athletes groups. This technique provided a large enough sample sizes in both the high and low EI groups and using a $40 \%$ of the team reporting cut-off ensured a more accurate distribution of athlete sampling for each team.

Research Hypotheses

Based on previous theoretical and empirical literature and the intuition of the investigator, the following hypotheses were predicted for the results of the current study. It was hypothesized that in comparison to the lower EI coached athletes group, the higher EI coached athletes group will have:

1. Stronger coach-athlete relationships assessed using the sub-scale scores from the athlete version of the Coach-Athlete Relationship Questionnaire (CART-Q; Appendix E; Jowett \& Ntoumanis, 2004)

2. Greater task-involving motivational climate assessed using the higher-order motivational climate scores from the Perceived Motivational Climate in Sport Questionnaire-2 (PMCSQ-2; Appendix F; Newton et al., 2000)

3. Higher athlete sport participation satisfaction assessed using single item score from the athlete demographic questionnaire (see Appendix C).

4. Perceptions of athletes that coaches are more effective at knowing how to motivate players assessed using single item score from the athlete demographic questionnaire.

\section{Data Analysis}

The SPSS statistical package v. 14.0 was used for all statistical analyses. Descriptive statistics, including means and standard deviations, was collected for all participants (coaches and athletes) for all dependent variables. Independent $t$-tests was calculated by comparing "High 
EI coached athletes" group versus "Low EI coached athletes" group on mean scores for each dependent variable: (1) coach - athlete relationship assessed using the sub-scale scores from the athlete version of Coach-Athlete Relationship Questionnaire (CART-Q; Appendix E; Jowett \& Ntoumanis, 2004); (2) athletes' perceived motivational climate assessed using the higher-order motivational climate scores from the Perceived Motivational Climate in Sport Questionnaire-2 (PMCSQ-2; Appendix F; Newton et al., 2000); (3) athlete's perceived coaching effectiveness of coach assessed using athlete demographic questionnaire (see Appendix C); (4) athlete's perception of coach's ability to motivate players assessed using single item score from the athlete demographic questionnaire; and (5) athlete's sport participation satisfaction assessed using the single item score from the athlete demographic questionnaire. In addition, simple Pearson correlation coefficients was run between each of the dependent variables. Significance levels was set at $p<.05$.

\section{Results}

The current results are based on the 232 athletes and 98 coaches from Phase I and the subset of 81 athletes and 7 coaches that were analyzed in Phase II.

\section{Descriptive Statistics of Athletes and Coaches}

Descriptive statistics indicated that out of the 232 athletes that completed the questionnaire, 37\% were freshman (see Table 2). Overall, the athletes were somewhat satisfied with their college soccer experience ( six point scale; $\mathrm{M}=4.06, \mathrm{SD}=1.21$ ) and felt a strong coach - athlete relationship with their coach (seven point scales; Closeness was $\mathrm{M}=5.61, \mathrm{SD}=$ 1.3, Commitment was $\mathrm{M}=4.89, \mathrm{SD}=1.29$. Complementarity was $\mathrm{M}=5.38, \mathrm{SD}=1.2$ ). In addition the athletes reported both relatively high Task $(\mathrm{M}=59.49, \mathrm{SD}=21.5)$ and Ego $(\mathrm{M}=$ 57.49, $\mathrm{SD}=19.5)$ motivational climate. 
Descriptive Statistics indicated that out of the 98 coaches that completed the demographic questionnaire, $31 \%$ were in the age range of $30-39$ year old, $48.5 \%$ had obtained a MA degree or higher, and 56\% played wither DI, DII, or DIII soccer in college (see Table 1). On average, coaches had eight years of total college soccer experience as a head coach $(\mathrm{M}=8.15, \mathrm{SD}=5.09)$ and coached their current team for about seven years $(\mathrm{M}=6.78, \mathrm{SD}=4.87)$. For me detail demographic information on the coaches who formed the EI groups please see Table 1.

\section{Correlations with Athlete CART-Q and PMCSQ-2 scores}

Correlations were run among CART-Q and PMCSQ-2 scores and demographic variables to see if any relationships existed between coach-athlete relationships, perceived motivational climate, winning percentage, statistician with college soccer experience, and overall coach effectiveness (see Table 3). The level of probability to determine significance was set at .05 for all statistical analyses unless specified otherwise.

Overall, the total CART-Q score is positively and significantly correlated with College Soccer Satisfaction, $r(232)=.57, \mathrm{p}<.01$, and Coach Effectiveness, $r(232)=.74, \mathrm{p}<.01$ indicating that an athlete's perceived strength of his coach-athlete relationship was associated with higher scores on athlete's soccer satisfaction and perception of his coach's effectiveness. The Ego sub-score from the PMCSQ-2 was positively and significantly correlated with the PMCSQ-2 sub-score Task, $r(232)=.54, \mathrm{p}<.01$ and Coach Effectiveness, $r(232)=.62, \mathrm{p}<.01$. The Task sub-score from the PMCSQ-2 was negatively and significantly correlated with Coach Effectiveness ratings, $r(232)=.40, \mathrm{p}<.01$ and coach-athlete relationship scores, $r(232)=-.21$, $\mathrm{p}<.01$. There was also a positive and significant correlation between College Soccer Satisfaction and Coach Effectiveness, $r(232)=.65, \mathrm{p}<.01$. In summary, a higher perceived Ego motivational climate score was associated with higher athlete ratings of coach effectiveness. In 
addition, a higher perceived Ego motivational climate score was associated with a higher perceived Task motivational climate score. Alternatively, a higher perceived Task motivational climate score was associated with lower athlete ratings of coach effectiveness.

\section{Correlations with Coach MSCEIT Scores}

Correlations were run among the four MSCEIT branch scores and demographic variables using the data set of 28 coaches that completed both the MSCEIT and the demographics questionnaire. This analysis was conducted to see if any relationships existed between a coach's emotional intelligence and number of games coached, career winning percentage, and the athletes' self-perception of effectiveness (see Table 4).

Overall, very few of the EI branch scores were significantly correlated with any of the demographic variables. The exception is the EI Branch 1 score (emotional perception), which was negatively correlated with Games Coached, $r(28)=-.41, \mathrm{p}<.01$. This result suggests that more years coaching is associated with lower scores on the EI branch one factor. In addition, there was also a positive and significant correlation between Career Win \% and self-ratings of Coach Effectiveness, $r(28)=.41, \mathrm{p}<.01$. This relationship can also be found in the athlete group (see Table 3).

Independent T-Test Between Higher EI Coached Athlete and Lower EI Coached Athlete Groups

The major hypotheses of this study were centered on comparing CART-Q, PMCSQ-2, and demographic variables between athletes who were coached by higher EI scoring coaches and athletes who were coached by lower EI scoring coaches. T-Test grouping protocol is outlined in the Procedures of the Methods section. Once groupings were established, T-tests were conducted to investigate our experimental hypotheses (see Table 5), and Cohen's d estimates are reported as the effect size measure. 
First, it was hypothesized that in comparison to the lower EI coached athletes group, the higher EI coached athletes group would have stronger coach-athlete relationships assessed using the overall score from the athlete version of the Coach-Athlete Relationship Questionnaire. Ttests were conducted on each of the three CART-Q sub-scores and results of the t-tests were significant: Closeness was $t(78)=-2.86, \mathrm{p}=.005, \mathrm{~d}=.639$; Commitment was $t(78)=-2.79, \mathrm{p}=$ $.007, \mathrm{~d}=.621$; Complimentarity was $t(78)=-2.47, \mathrm{p}=.016, \mathrm{~d}=.562$. In each case, the means were significantly different in the opposite direction of the hypotheses in that athletes who were coached by lower EI scoring coaches rated the relationship as stronger than athletes who were coaches by higher EI coaches.

Second, it was also hypothesized that in comparison to the lower EI coached athletes group, the higher EI coached athletes group would have greater task-involving motivational climate assessed using the higher-order motivational climate scores from the Perceived Motivational Climate in Sport Questionnaire-2. T-tests were conducted on each of the two PMCSQ-2 sub-scores and results of the t-tests were not significant: Ego was $t(72)=-.581, \mathrm{p}=$ $.563, \mathrm{~d}=.134 ;$ Task was $t(72)=1.164, \mathrm{p}=.248, \mathrm{~d}=.270$.

Third, it was hypothesized that in comparison to the lower EI coached athletes group, the higher EI coached athletes group would have higher athlete sport participation satisfaction. A ttest was conducted on each the College Soccer Satisfaction variable and results of the t-test was not significant $t(79)=-1.51, \mathrm{p}=.134, \mathrm{~d}=.337$

Lastly, it was hypothesized that in comparison to the lower EI coached athletes group, the higher EI coached athletes group would have higher perception ratings that coaches are more effective at knowing how to motivate players. A t-test was conducted on each the Coach Ability 
to Motivate You variable and results of the t-test was not significant $t(70)=-1.32, \mathrm{p}=.191, \mathrm{~d}=$ .316

Although not one of the original hypothesis, there was a significant difference between the lower EI coached athletes group and the higher EI coached athletes group on winning percentage, $t(70.5)=-3.59, \mathrm{p}=.001, \mathrm{~d}=.773$. This result is interesting because it is in the same direction than the CART-Q results with the lower EI coached athlete group having a higher winning percentage than the higher EI coached athlete group.

\section{Discussion}

The purpose of this investigation was two-fold. The first purpose was to investigate factors that may be linked to winning, strength of coach-athlete relationships, and college soccer satisfaction in DIII men's soccer players. The second purpose was to examine if higher EI coached athletes varied compared to lower EI coached athletes in their strength of the coachathlete relationship, perceived motivational climate, college soccer satisfaction, coaches' ability to motivate, and winning percentage. Results of the investigation indicate that lower EI coached athletes reported stronger coach-athlete relationships compared to higher EI coached athletes but no significant difference between the groups were reported on perceived motivational climate, college soccer satisfaction, and coaches' ability to motivate. Interestingly, compared to higher EI coached athletes, lower EI coached athletes also reported a higher winning percentage for the season.

\section{Differences Between Higher EI Coached Athletes and Lower EI Coached Athletes}

Results of this study indicate that lower coach EI is associated with players perceiving more compassion, commitment, complementarity in their coach-athlete relationship as measured by CART-Q. This finding goes against research from non-sport domains that indicate EI affects 
a leader's ability to build strong interpersonal relationships and motivate followers (e.g. Brackett et al., 2003; Palmer et al., 2000; Salovey et al., 2002; Weinberg \& McDermott, 2002). Similarly, research within the field of sport psychology indicates emotions from coaches and teammates play a vital part in team development and performance (Botterill \& Brown, 2002; Jones, 2003; Jones \& Swain, 1995; Lazarus, 2000). Specifically, findings by Magyar and colleagues (2007) revealed EI plays in important factor in a leader's (physical education teachers) ability to effectively teach in a caring manner. Thus, the findings that lower EI coached athletes report stronger and more positive relationships with their coaches is inconsistent with previous research. This suggests there may be other dynamics within the coaching domain that affects relationships and the role EI plays.

Before collegiate athletes are even on their team, athletes gain familiarity about the coach, his coaching style, and the team's motivational climate through the recruiting process. Based on this familiarity, athletes may pick what school to enroll based on which coach they perceive to be the best match with their coaching preferences. For some athletes a coach's EI may not matter and they would prefer playing for a coach with a more authoritative coaching style. Interestingly, when comparing the demographic data of the coaches who were used to form EI groups (see Table 1), the low EI coaches were on average older (40-49 age range) and had more college head coaching experience $(M=9.66$ years $)$ compared to the high EI coaches (30-39 age range; $M=7$ years as head college soccer coach). More seasoned college coaches can rely more on their experienced reputation to build respect and trust from athletes, whereas, less experienced coaches must rely on their ability to build caring relationships in order to build trust and respect with their athletes. 
Similarly, seminal psychological research on the implicit personality theory (IPT) indicates that often the first traits an individual recognizes in other people influence their interpretation and perception of later ones because of their expectations (Kelly, 1945). Thus, as IPT suggests because collegiate athletes gain familiarity with their coach and team during the recruiting process, they develop positive expectations about their coach and team. Once the athlete reaches college and is on their team, these positive expectations may lead an athlete to see a coach and their college soccer experience in a more favorable light even when the coach may be poor at building relationships and motivating players. Thus, the implicit personality theory could be a potential explanation why lower coach EI is associated with stronger coach-athlete relationships.

Another interesting finding was that the average winning percentage of the lower EI coached athletes was significantly higher than the average winning percentage of the higher EI coached athletes. What makes this finding of particular interest is that it is counter to our original experimental hypothesis, which was based on previous sport research that suggests several specific psychological skills under the umbrella of EI, including emotional awareness and emotion regulation, have been found to play critical roles in positively affecting athletic performance for teams and individual athletes (Hanin, 2000; Jones, 2003; Mageau \& Vallerand, 2003; Ravizza, 2006; Vallerand \& Blanchard, 2000).

One possible explanation of this finding is that the measure of winning percentage was the winning percentage of the team this season when the completed they survey. Thus, using a career winning percentage of the coach may be a more accurate measure of winning and provide a different result. In addition, athletes often place a high value on winning, especially male athletes who are in general more competitive, and expect a particular style of coaching that 
perceived to be aligned with winning focused motivational climate. Thus, our hypothesis that a task motivational climate will have a positive relationship with winning may actually be wrong.

Interestingly, the finding that lower EI coaches athletes had a higher winning percentage on average did not align with results of our correlation analysis of athlete experimental variables that reveal that increases in CART-Q, Task motivational climate, coaching effectiveness variables were all positively and significantly correlated with winning percentage.

Lastly, while the aforementioned results suggest lower coach EI is associated with higher coach-athlete relationships, results comparing higher EI coached athletes to lower EI coached athletes on Ego and Task PMCSQ-2 subscales were not significant due to lower than desired power $(\sim .70)$ and sample size. Thus, an increased sample size could help clarify results near the significance threshold. Although not significant, it is important to note that the t-test results centered on the PMCSQ-2 were in alignment with the research hypothesis that in comparison to the lower EI coached athletes group, the higher EI coached athletes group reported greater taskinvolving motivational climate $(d=.27)$. Future studies with larger sample sizes of athletes in each of these two groups might find significance with this small to moderate effect.

\section{Correlation Results}

The athlete correlational findings revealed that Ego motivational climate was positively and significantly correlated with CART-Q and Coaching Effectiveness variables whereas Task motivational climate was negatively and significantly correlated with CART-Q, Winning Percentage, College Soccer Satisfaction, and Coach Effectiveness variables. These findings are contrary to our research hypotheses that were based on seminal goal orientation theory research (Newton et al., 2000; Nicholls, 1989). 
Although research findings are relatively inconclusive, research on elite athletes could help explain the findings. Research suggests elite athletes perceive they need less social support from coaches and team because they get social support from other sources (Fletcher \& Hanton, 2003; Rees \& Hardy, 2000). Thus, the fact that social support from a coach or team is sometimes not as important may suggest that some elite athletes may be able to build stronger relationship with coaches that establish less Task and a more Ego motivational climates.

Similarly, a Beam and Serwatka (2004) study suggests that while college female athletes prefer coaches who have situational consideration and focus on coaching technique, male college athletes showed preference for autocratic coaching styles. Since this study only used male athletes, our results maybe be different than and ungeneralizable to female athletes. Thus, the male athletes in this study may value and have stronger coach-athlete relationships with coaches that use more of an autocratic style and stress competition and winning - all factors associated with an Ego motivational climate. This gender difference could explain why our research results revealed that Ego motivational climate was positively and significantly correlated with CART-Q and Coaching Effectiveness.

\section{Limitations}

There are several limitations to this study that have already been discussed above. With that said, there are three key limitations the need to be addressed in more detail: i) failing to assess the role an assistant coach plays in the EI coach-athlete relationship dynamic, ii) sample size, and iii) grouping method.

This study did not adequately investigate the entire coaching staff's EI and how EI may affect the coaching staff dynamic and coach-athlete relationships. The head coach's EI and interaction with players was exclusively analyzed whereas, most if not all teams also had an 
active assistant coach that interacted with both head coach and team-members. In hindsight, this was a major limitation of this study. By assessing only the head coach's EI, only part of the relationship between coach EI and coach-athlete relationships is addressed.

Depending on the coaching staff's dynamic, a head coach most likely has different roles and relationships with players compared to an assistant coach. For example, on some teams a head coach might play the "good cop" role with the assistant coach taking on a "bad cop" role, where on other teams the roles may be reversed. Depending on the roles a head coach and his assistant take on will affect how players rate the coach-athlete relationship. Furthermore, by only focusing on the head coach and not knowing anything about the roles of assistant coaches, our results may provide an incomplete picture of the role of coach EI has on coach-athlete relationships at best. Thus, future research needs to assess not only the head coach's EI and subsequent player coach-athlete relationship ratings but also the assistant coaches'.

A second limitation of this study was one of sample size. Specifically there is a lack of sample distribution for winning percentage data because there are only four teams and four different team winning percentages being represented in the higher EI coached athlete group and only three teams and three different team winning percentages being represented in the lower EI coached athlete group. Thus, with only four overall winning percentages for the high EI group and three winning parentages for the low EI group, the mean winning percentage is not a good representation and there is not enough variability in scores to achieve an accurate analysis. For example, one of the teams that was included in the lower EI coached athlete group was coached by a coach with one of the highest active winning percentages in NCAA DIII soccer. Predictably, this season his team had the one of the highest season winning percentage of all teams surveyed, well above $70 \%$. This winning percentage outlier existing simultaneously with 
decreased variability could inflate effect size. However, in a larger sample size with more team winning percentage represented this specific finding might not be as significant or have as large of an effect size. Thus, this turns out to be not only a sample distribution limitation, but also an EI grouping limitation.

A third limitation of study was one of grouping criteria. Future studies need to establish better data collection and EI grouping techniques that will increase questionnaire response rates and sample sizes for each group without compromising the use of the most extreme EI coach scores to establish grouping criteria.

\section{Implications and Future Directions}

As previously stated, it is well established within in the business domain, that key determinants of motivation and effective leadership, such as the ability to display optimism, motivate, and build morale, can be linked to emotional intelligence (Caruso \& Wolfe, 2004). With that said, it is currently unclear the extent EI may play in developing social attachments, motivation, or leadership effectiveness within sport (e.g. coaching). Future research from a topdown perspective could extend EI and leadership research within the corporate domain, and assess the role EI has on coaching effectiveness. More specifically, questions should include: Do higher EI coaches have increased team cohesion and lower player burn-out and drop-out rates? Second, this study took a first attempt looking at if EI affects how well a coach can motivate his players. More specific follow up questions could include: how does a coach's EI affect his ability to be aware of his players emotional state, assess what type of emotional motivation is best for that player, and then strategically regulate his emotions to skillfully "push the motivational buttons" of this individual player? 
Lastly, many occupational fields have begun to incorporate EI into employee training programs including mental and physical health care (Evans \& Allen, 2002) and corporate management (George, 2000) as an attempt to develop employees who are better leaders with better interpersonal skills. Relating this back to sport, Weiss and Ferrer-Caja (2002) suggested that the ways in which coaches emotionally respond to athletes can significantly affect their athletes' perceived competence, global self-worth, affect, motivational orientation, and actual participation. Furthermore, surveys of athlete motivation have identified the coach and their subsequent coaching behaviors as a major factor in determining whether athletes choose to continue or drop out of sport (Lee, 1999; Weiss \& Ferrer-Caja, 2002).

In closing, given the newness of emotional intelligence in sport and coaching research, the present study examined the relationship between them. With many significant correlations and t-scores reported, EI maybe a critical ability that is fundamental to coaching, the coachathlete relationship, and motivation within a competitive collegiate sport domain. Therefore, future research in these areas may provide continued insight to how coaching effectiveness can be better understood, trained, and enhanced. 


\section{REFERENCES}

Allen, J., \& Cohen, J. (2006). Emotional intelligence in classrooms and in schools: What we see in the educational setting In K. Murphy (Ed.), A critique of emotional intelligence: What are the problems and how can they be fixed? (pp. 125-139). Mahwah, New Jersey LEA.

Balaguer, I., Crespo, M., \& Duda, J. L., (1996). The relationship of motivational climate and athletes' goal orientation to perceived/preferred leadership style. Journal of Sport and Exercise Psychology, 18, 13.

Barach, J. A., \& Eckhardt, D. R. (1996). Leadership and the job of the executive. Westport, CT: Quorum Books.

Beam, J., Serwatka, T., \& Wilson, W. (2004). Preferred leadership of NCAA Division I and II intercollegiate student-athletes. Journal of Sport Behavior, 27(1), 3-17.

Botterill, C., \& Brown, M. (2002). Emotion and perspective in sport. International Journal of Sport Psychology, 33(1), 38-60.

Brackett, M. A., \& Salovey, P. (2006). Measuring emotional intelligence with the MayerSalovey-Caruso Emotional Intelligence Test (MSCEIT). Psicothema, 18, 34-41.

Brustad, R. (1988). Affective Outcomes in Competitive Youth Sport: The Influence of Intrapersonal and Socialization Factors. Journal of Sport \& Exercise Psychology, 10(3), 307-321.

Caruso, D. R., \& Wolfe, C. J. (2004). Emotional intelligence and leadership development. In D. V. Day, S. J. Zaccaro and S. M. Halpin (Eds.), Leader development for transforming organizations: Growing leaders for tomorrow. (pp. 237-263). Mahwah, NJ, US: Lawrence Erlbaum Associates Publishers. 
Clews, G. J., \& Gross, J. B. (1995). Individual and social motivation in Australian sport. In Sport psychology: Theory, applications and issues. (pp. 90-121). Brisbane, Australia: John Wiley.

Darwin, C. (2005). The expression of the emotions in man and animals. New York: Kessinger Publishing.

Ekman, P. (1973). Darwin and facial expression: A century of research in review. New York: Academic Press.

Elam, C. L. (2000). Use of 'emotional intelligence' as one measure of medical school applicants' noncognitive characteristics. Academic Medicine, 75(5), 445-446.

Evans, D., \& Allen, H. (2002). Emotional intelligence: It's role in training. Nursing Times, 98, 41-42.

Fletcher, D., \& Hanton, S. (2003). Sources of organizational stress in elite sports performers. Sport Psychologist, 17(2), 175-195.

Frijda, N. H., \& Mesquita, B. (1994). The social roles and functions of emotions. In S. Kitayama and H. Markus (Eds.), Emotion and culture: Empirical studies of mutual influence (pp. 51-87). Washington, DC: APA.

Fullam, A. (2002). Adult attachment, emotional intelligence, health, and immunological responsiveness to stress. Unpublished dissertation, Rutgers University.

George, J. M. (2000). Emotions and leadership: The role of emotional intelligence. Human Relations, 53(8), 1027-1055.

Goleman, D., Boyatzis, R. E., \& McKee, A. (2002). Primal leadership: Realizing the power of emotional intelligence. Boston, MA: Harvard Business School Press. 
Hanin, Y. L. (2000). Soccer and emotion: Enhancing or impairing performance? In In Soccer \& science (p.68-89), Copenhagen, Denmark, Institute of Exercise and Sport Sciences.

Hoigaard, R., \& Jorgensen, A. (2007). Coaching conversations - A way of fostering athletes to peak performance. USOC Olympic Coach E-Magazine, 19.

Janssen, J., \& Dale, G. A. (2002). The seven secrets of successful coaches: How to unlock and unleash your team's full potential. Tucson, AZ: Winning the Mental Game.

Jones, G. (2002). Performance excellence: A personal perspective on the link between sport and business. Journal of Applied Sport Psychology, 14, 268-281.

Jones, M.V. (2003). Controlling emotions in sport. The Sport Psychologist, 17, 471-486.

Jones, G., \& Swain, A. (1995). Predispositions to experience debilitative and facilitative anxiety in elite and nonelite performers. Sport Psychologist, 9(2), 201-211.

Jowett. S. (2007). Interdependence analyisis and the 3+1Cs in the coach-athlete relationship. In S. Jowett \& D. Lavallee (Eds.), Social Psychology in Sport (pp. 15-27). Champaign, IL: Human Kinetics.

Jowett, S., \& Cockerill, I. M. (2003). Olympic medalists' perspective of the athlete-coach relationship. Psychology of Sport and Exercise, 4, 313-331.

Jowett, S. \& Meek, G. A. (2000). The coach-athlete relationship in married couples: an exploratory content analysis. The Sport Psychologist, 14, 157 - 175.

Jowett, S., \& Ntoumanis, N. (2004). The coach-athlete relationship questionnaire (CART-Q): development and initial validation. Scandinavian Journal of Medicine and Science in Sports, 14(4), 245-257.

Jowett, S., \& Poczwardowski, A. (2007). Understanding the coach-athlete relationship. In S. Jowett and D. Lavallee (Eds.), Social psychology in sport (pp. 3-14). Champaign, 


\section{IL: Human Kinetics.}

Kelly, G. A. (1955). The psychology of personal constructs (Vols. 1 and 2). New York: Norton.

Lazarus, R. S. (2000). How emotions influence performance in competitive sports. The Sport Psychologist, 14(3), 229-252.

Lee, M. (Ed.). (1999). Coaching children in sport: Principles and practice. London: Routledge.

Mageau, G. A., \& Vallerand, R. J. (2003). The coach-athlete relationship: a motivational model. Journal of Sports Sciences, 21(11), 883-904.

Magyar, T. M., Guivernau, M. R., Gano-Overway, L. A., Newton, M., Kim, M.-S., Watson, D. L., \& Fry, M. (2007). The influence of leader efficacy and emotional intelligence on personal caring in physical activity. Journal of Teaching in Physical Education, 26(3), 310-319.

Martin, S.B., Dale, G.A., \& Jackson, A.W. (2001). Youth coaching preferences of adolescent athletes and their parents. Journal of Sport Behavior, 24 (2), 196-215.

Mayer, J. D., Caruso, D. R., \& Salovey, P. (1999). Emotional intelligence meets traditional standards for an intelligence. Intelligence, 27(4), 267-298.

Mayer, J. D., Salovey, P., \& Caruso, D. R. (2002). Mayer-Salovey-Caruso Emotional Intelligence Test (MSCEIT): user's manual. Toronto: Multi-Health Systems.

Mayer, J. D., Salovey, P., Caruso, D. R., \& Sitarenios, G. (2003). Measuring emotional intelligence with the MSCEIT V2. 0. Emotion, 3(1), 97-105.

McCann, S. (1999). Emotional intelligence: The secret of athletic excellence. Olympic Coach, $9(2), 8-9$. 
Meyer, B. B., \& Fletcher, T. B. (2007). Emotional intelligence: A theoretical overview and implications for research and professional practice in sport psychology. Journal of Applied Sport Psychology, 19, 1-15.

Newton, M., Duda, J. L., \& Yin, Z. (2000). Examination of the psychometric properties of the Perceived Motivational Climate in Sport Questionnaire-2 in a sample of female athletes. Journal of Sports Sciences, 18, 275-290.

Nicholls, J. G. (1989). The competitive ethos and democratic education. Cambridge, MA: Harvard University Press.

Ntoumanis, N., \& Biddle, S. J. H. (1999). A review of motivational climate in physical activity. Journal of Sports Sciences, 17(8), 643-665.

Palmer, B.,Walls, M., Burgess, Z., \& Stough, C. (2000). Emotional intelligence and effective leadership. Leadership and Organizational Development Journal, 22, 5-10.

Pau, A. K., \& Croucher, R. (2003). Emotional intelligence and perceived stress in dental undergraduates. Journal of Dental Education, 67(9), 1023-1028.

Poczwardowski, A., Barott, J.R., \& Peregoy, J.J. (2002). The athlete and coach: Their relationships and its meaning - Methodological concerns and research process. International Journal of Sport Psychology, 33, 98-115.

Ravizza, K. (2006). Increasing awareness for sport performance. In J. Williams (Ed.), Applied Sport Psychology (5 ed.). New York: McGraw-Hill.

Rees, T., \& Hardy, L. (2000). An investigation of the social support experiences of high-level sports performers. Sport Psychologist, 14(4), 327-347. 
Reinboth, M., \& Duda, J. L. (2006). Perceived motivational climate, need satisfaction and indices of well-being in team sports: A longitudinal perspective. Psychology of Sport \& Exercise, 7(3), 269-286.

Salovey, P., \& Mayer, J. D. (1990). Emotional intelligence. Imagination, Cognition and Personality, 9, 185-211.

Salovey, P., Mayer, J. D., \& Caruso, D. (2002). The positive psychology of emotional intelligence. In C. R. Snyder, and S. J. Lopez (Eds.), Handbook of positive psychology (pp. 159-171). London: Oxford University Press.

Theeboom, M., De Knop, P. and Weiss, M.R. (1995). Motivational climate, psychological response, and motor skill development in children's sport: A Weld-based intervention study. Journal of Sport and Exercise Psychology, 17, 294-311.

Thelwell, R., Lane, A., Weston, N., \& Greenlees, L. (2008). Examining relationships between emotional intelligence and coaching efficacy. International Journal of Sport \& Exercise Psychology, 6(2), 224-235.

Vallerand, R. J., \& Blanchard, C. M. (2000). The study of emotion in sport and exercise. In Y. L. Hanin (Ed.), Emotions in sport (pp. 3-38). Champaign, IL: Human Kinetics.

Wankel, L., \& Kreisel, P. (1985, March). Factors underlying enjoyment of youth sports: Sport and age group comparisons. Journal of Sport Psychology, 7(1), 51-64.

Weinberg, R., \& McDermott, M. (2002). A comparative analysis of sport and business organizations: Factors perceived critical for organizational success. Journal of Applied Sport Psychology, 14(4), 282-298. 
Weiss, M. R., \& Ferrer-Caja, E. (2002). Motivational orientations and sport behavior. In T. Horn (Ed.), Advances in sport psychology (2 ed., pp. 101-184). Champaign, IL: Human Kinetics.

Zizzi, S. J., Deaner, H. R., \& Hirschhorn, D. K. (2003). The relationship between emotional intelligence and performance among college baseball players. Journal of Applied Sport Psychology, 15(3), 262-269. 
Table 1

$\underline{\text { Descriptive Data for Coaches }}$

\begin{tabular}{|c|c|c|c|c|c|c|}
\hline \multirow[b]{2}{*}{ Age } & \multicolumn{2}{|c|}{$\begin{array}{c}\text { ALL } \\
(\underline{\mathrm{n}}=98)\end{array}$} & \multicolumn{2}{|c|}{$\begin{array}{l}\text { Low EI } \\
(\underline{n}=3)\end{array}$} & \multirow[b]{2}{*}{$\underline{\underline{x}}$} & \multirow{2}{*}{$\begin{array}{l}\text { High EI } \\
(\underline{\mathrm{n}}=4)\end{array}$} \\
\hline & $\underline{f x}$ & $\%$ & $\underline{f x}$ & $\underline{\%}$ & & \\
\hline $20-29$ & 10 & 7.5 & 0 & 0 & 1 & 25 \\
\hline $30-39$ & 42 & 31.3 & 1 & 33.3 & 2 & 50 \\
\hline $40-49$ & 24 & 17.9 & 1 & 33.3 & 1 & 25 \\
\hline $50-59$ & 18 & 13.4 & 1 & 33.3 & 0 & 0 \\
\hline $60+$ & 4 & 3.0 & 0 & 0 & 0 & 0 \\
\hline \multicolumn{7}{|l|}{ Education Obtained } \\
\hline HS & 2 & 1.5 & 1 & 33.3 & 0 & 0 \\
\hline $\mathrm{BA} / \mathrm{BS}$ & 30 & 22.4 & 0 & 0 & 2 & 50 \\
\hline MA & 56 & 41.8 & 1 & 33.3 & 2 & 50 \\
\hline Higher than MA & 9 & 6.7 & 1 & 33.3 & 0 & 0 \\
\hline \multicolumn{7}{|l|}{ College Playing Experience } \\
\hline None & 13 & 9.7 & 1 & 33.3 & 1 & 25 \\
\hline NAIA & 7 & 5.2 & 0 & 0 & 0 & 0 \\
\hline DIII & 18 & 13.4 & 0 & 0 & 1 & 25 \\
\hline DII & 10 & 7.5 & 1 & 33.3 & 0 & 0 \\
\hline DI & 47 & 35.1 & 1 & 33.3 & 2 & 50 \\
\hline & Mean & $\underline{\mathrm{SD}}$ & Mean & $\underline{\mathrm{SD}}$ & Mean & $\underline{\mathrm{SD}}$ \\
\hline Total Years Coaching & 8.15 & 5.09 & 9.66 & 4.49 & 7 & 4.3 \\
\hline Year Coaching Current Team & 6.78 & 4.87 & 8.33 & 3.1 & 5 & 3 \\
\hline Career Winning Percentage & .47 & .19 & 47.33 & 14.3 & 36 & 21.3 \\
\hline Coach Ed Events Per Year & 1.48 & 1.35 & 1 & 0 & 1 & 1.2 \\
\hline Rated Coaching Ed Importance & 4.64 & 1.12 & 4.66 & .94 & 4.75 & 1.3 \\
\hline
\end{tabular}

Note: Rated Coaching Ed Importance is based on a 6-point Likert scale ranging from 1 (Not at all important) to 6 (Very important). 
Table 2

Descriptive Data for Athletes

\begin{tabular}{|c|c|c|c|c|c|c|}
\hline & \multicolumn{2}{|c|}{$\begin{array}{c}\text { ALL } \\
(\underline{\mathrm{n}}=232)\end{array}$} & \multicolumn{2}{|c|}{$\begin{array}{l}\text { Higher EI } \\
(\underline{\mathrm{n}}=35)\end{array}$} & \multicolumn{2}{|c|}{$\begin{array}{c}\text { Lower EI } \\
(\underline{\mathrm{n}}=46)\end{array}$} \\
\hline & Mean & $\mathrm{SD}$ & Mean & SD & Mean & $\mathrm{SD}$ \\
\hline Year in College & 2.24 & 1.16 & 2.12 & 1.12 & 2.11 & 1.12 \\
\hline & $\underline{f x}$ & $\underline{\%}$ & $\underline{\mathrm{fx}}$ & $\underline{\%}$ & $\underline{f x}$ & $\underline{\%}$ \\
\hline Freshmen(1) & 86 & 36.9 & 13 & 38.2 & 18 & 39.1 \\
\hline Sophomore(2) & 52 & 22.3 & 10 & 29.4 & 13 & 28.3 \\
\hline Junior(3) & 48 & 20.6 & 5 & 14.7 & 7 & 15.2 \\
\hline Senior(4) & 45 & 19.3 & 6 & 17.6 & 8 & 17.4 \\
\hline $5^{\text {th }}$ Year Senior(5) & 1 & .4 & 0 & 0 & 0 & 0 \\
\hline & Mean & $\mathrm{SD}$ & Mean & SD & Mean & $\mathrm{SD}$ \\
\hline Total Years Playing Soccer & 11.82 & 3.77 & 12.11 & 2.98 & 11.26 & 3.58 \\
\hline College Starts & 12.38 & 16.3 & 10.29 & 13.8 & 15.43 & 20.4 \\
\hline College Soccer Satisfaction & 4.06 & 1.21 & 3.83 & 1.27 & 4.24 & 1.16 \\
\hline Closeness w/ Coach & 5.61 & 1.3 & 5.39 & 1.1 & 6.04 & .94 \\
\hline Commitment w/ Coach & 4.89 & 1.29 & 4.62 & 1.1 & 5.26 & .95 \\
\hline Complementarity w/ Coach & 5.38 & 1.2 & 5.18 & 1.01 & 5.73 & .94 \\
\hline Ego & 59.49 & 19.5 & 62.43 & 13.2 & 64.0 & 9.9 \\
\hline Task & 57.49 & 21.5 & 64.5 & 15.4 & 60.7 & 12.48 \\
\hline
\end{tabular}

Note: College Soccer Satisfaction is based on a 6-point Likert scale ranging from 1 (Extremely dissatisfied) to 6 (Extremely satisfied).

Note: Closeness w/ Coach, Commitment w/ Coach, Complementarity w/ Coach averages come from the corresponding sub-scale questions on the CART-Q which is based on a 7-point Likert scale ranging from 1 (Strongly disagree) to 7 (Strongly agree).

Note: Ego and Task averages come from the corresponding sub-scale questions on the PMCSQ-2 which is based on a 5-point Likert scale ranging from 1 (Strongly disagree) to 5 (Strongly agree). 
Table 3

Correlations with Athlete CART-Q and PMCSQ-2 scores ( $\mathrm{n}=232)$

\begin{tabular}{|c|c|c|c|c|c|c|}
\hline & 1 & 2 & 3 & 4 & 5 & 6 \\
\hline 1. Total CART-Q & --- & $.29 * *$ & $-.21 * *$ & $.28 * *$ & $.57 * *$ & $.74 * *$ \\
\hline 2. Ego & & --- & $.54 * *$ & .11 & $.17^{*}$ & $.62 * *$ \\
\hline 3. Task & & & --- & $-.14^{*}$ & $-.28 * *$ & $-.40 * *$ \\
\hline 4. Win Percentage & & & & --- & $.41^{* *}$ & $.43 * *$ \\
\hline 5. College Soccer Satisfaction & & & & & --- & $.65^{* *}$ \\
\hline 6. Coach Effectiveness & & & & & & --- \\
\hline
\end{tabular}

**Correlation is significant at the .01 level

*Correlation is significant at the .05 level

Note: Ego and Task come from the corresponding sub-scale questions on the PMCSQ-2 which is based on a 5-point Likert scale ranging from 1 (Strongly disagree) to 5 (Strongly agree).

Note: College Soccer Satisfaction is based on a 6-point Likert scale ranging from 1 (Extremely dissatisfied) to 6 (Extremely satisfied).

Note: Coaching Effectiveness is based on a 6-point Likert scale ranging from 1 (Not at all effective) to 6 (Very effective). 
Table 4

Correlations with Coach EI scores $(\mathrm{n}=28)$

\begin{tabular}{|c|c|c|c|c|c|c|c|}
\hline & 1 & 2 & 3 & 4 & 5 & 6 & 7 \\
\hline 1. EI Branch 1 & --- & $.45^{*}$ & .29 & .28 & $-.41 *$ & -.22 & -.20 \\
\hline 2. EI Branch 2 & & --- & .24 & $.41 *$ & -.37 & -.17 & -.19 \\
\hline 3. EI Branch 3 & & & --- & $.55^{* *}$ & .18 & -.04 & .24 \\
\hline 4. EI Branch 4 & & & & --- & .10 & .03 & .28 \\
\hline 5. Games Coached & & & & & --- & .19 & .12 \\
\hline 6. Career Win Percentage & & & & & & --- & $.41 *$ \\
\hline 7. Coach Effectiveness & & & & & & & --- \\
\hline
\end{tabular}

**Correlation is significant at the .01 level

*Correlation is significant at the .05 level

Note: Coaching Effectiveness is based on a 6-point Likert scale ranging from 1 (Not at all effective) to 6 (Very effective).

Note: EI Branch 1 = emotional perception (EP), EI Branch 2 = emotional integration to facilitate cognition (FC), EI Branch 3 = emotional understanding (EU), EI Branch 4 = emotional management (EM). 
Table 5

Independent T-Test between higher EI coached athlete and lower EI coached athlete groups

\begin{tabular}{|c|c|c|c|c|c|}
\hline & \multicolumn{2}{|c|}{ Higher EI $\underline{n}=34$} & \multicolumn{2}{|c|}{ Lower EI $\underline{n}=46$} & \multirow[b]{2}{*}{$\begin{array}{l}\underline{\text { Effect }} \\
\underline{\text { Size }(d)}\end{array}$} \\
\hline & $\underline{\mathrm{M}}$ & $\underline{\mathrm{SD}}$ & $\underline{\mathrm{M}}$ & $\underline{\mathrm{SD}}$ & \\
\hline Closeness & 5.39 & 1.09 & 6.04 & .939 & $.639^{* *}$ \\
\hline Commitment & 4.62 & 1.10 & 5.26 & .953 & $.621 * *$ \\
\hline Complementarity & 5.18 & 1.01 & 5.73 & .945 & $.562 * *$ \\
\hline \multicolumn{6}{|l|}{ PMCSQ-2 ${ }^{1}$} \\
\hline Ego & 62.43 & 13.24 & 64.00 & 9.93 & .134 \\
\hline Task & 64.53 & 15.37 & 60.75 & 12.49 & .270 \\
\hline Win Percentage & .351 & .137 & .515 & .267 & $.773 * *$ \\
\hline College Soccer Satisfaction & 3.83 & 1.272 & 4.24 & 1.158 & .337 \\
\hline Coach Ability to Motivate You & 3.97 & 1.180 & 4.37 & 1.346 & .316 \\
\hline
\end{tabular}

$* * t$ value is significant at the .01 level

$* t$ value is significant at the .05 level

${ }^{1}$ Higher EI $\underline{n}=30$, Lower EI $\underline{n}=44$

Note: Grouping 1 consisted of using MSCEIT total score and included the teams that had at least $40 \%$ of athletes reporting for the 4 highest coach EI scores and 3 lowest coach EI scores. 


\section{APPENDIX A}

COACH DEMOGRAPHIC QUESTIONNAIRE 


\section{COACH DEMOGRAPHIC QUESTIONNAIRE}

\section{PART 1: Please tell us a bit about who filled out this survey...}

1. Age: 20-29 years 30-39 years 40-49 years 50-59 years $60+$ years

2. Highest education degree obtained: H.S. Bachelor's Higher then MA

3. How many seasons have you been a head college soccer coach?

4. How many seasons have you coached this team?

5. What is your career college head coach win-loss record?

6. What is your conference win-loss record the last 4 years?

7. Please list any certifications/licenses you currently hold related to coaching:

8. How often have you attended/participated in a continuing coaching education workshop/event in the last year: Zero $\quad 1-2 \quad 3-4 \quad 5$ or more

Not at all important
Very important

9. How important is attending/participating in coaching education

$\begin{array}{llllll}1 & 2 & 3 & 4 & 5 & 6\end{array}$
workshops to your continuing growth/improvement as a coach?

PART 2: Please indicate how you view your effectiveness by circling the response that corresponds to your feelings toward each statement ( 1 = Not at all effective to 6 very effective). Please respond as candidly as possible and recall that there are no right or wrong answers.

\section{Not at all} effective

\section{Very effective}

1. How effective are you in building positive relationships with your players?

2. How effective are you in motivating players on your team?

3. How effective are you at being 'in tune' with your athlete's emotions?

4. Overall, how would you rate your effectiveness as a coach?

$\begin{array}{llllll}1 & 2 & 3 & 4 & 5 & 6\end{array}$

$\begin{array}{llllll}1 & 2 & 3 & 4 & 5 & 6\end{array}$

$\begin{array}{llllll}1 & 2 & 3 & 4 & 5 & 6\end{array}$

$\begin{array}{llllll}1 & 2 & 3 & 4 & 5 & 6\end{array}$


PART 3: Please indicate your level of agreement with each of the following statements by circling the response that corresponds to your feelings towards each statement. ( 1 = Strongly disagree to $6=$ Strongly agree). Please respond as candidly as possible and recall that there are no right or wrong answers.

\section{Strongly \\ Disagree}

1. As a coach, I have the ability to accurately perceive and

$\begin{array}{llllll}1 & 2 & 3 & 4 & 5 & 6\end{array}$
express emotions in myself and others.

2. As a coach, I have the ability to access and/or generate feelings that facilitate thought.

$\begin{array}{llllll}1 & 2 & 3 & 4 & 5 & 6\end{array}$

3. As a coach, I have the ability to understand emotions and

$\begin{array}{llllll}1 & 2 & 3 & 4 & 5 & 6\end{array}$
emotional knowledge.

4. As a coach, I have the ability to control/regulate my emotions.

$\begin{array}{llllll}1 & 2 & 3 & 4 & 5 & 6\end{array}$


EI, Coach-Athlete Relationships, and Motivation 46

\section{APPENDIX B}

COACH PERCEPTION OF COACH-ATHLETE RELATIONSHIPS MEASURE 


\section{COACH PERCEPTION OF COACH-ATHLETE RELATIONSHIPS MEASURE}

Directions: Please rate the quality of your relationship for every player on your team on the scale below $(1=$ poor to 6 excellent $)$. Please respond as candidly as possible and recall that there are no right or wrong answers.

\section{Poor}

Excellent

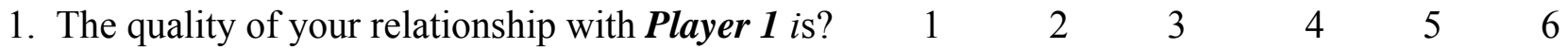

2. The quality of your relationship with Player 2 is? $\quad \begin{array}{lllllllll}2 & 2 & 3 & 4 & 5 & 6\end{array}$

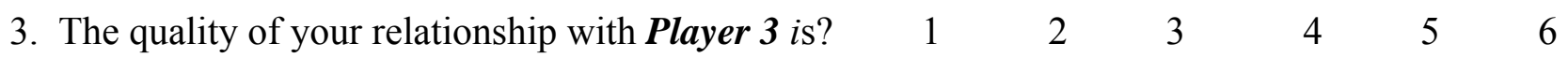

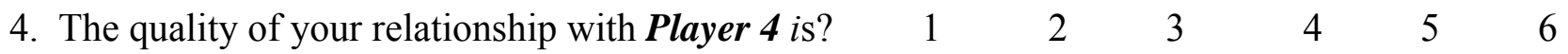

5. The quality of your relationship with Player 5 is? $\quad \begin{array}{lllllllll} & 1 & 2 & 3 & 4 & 5 & 6\end{array}$

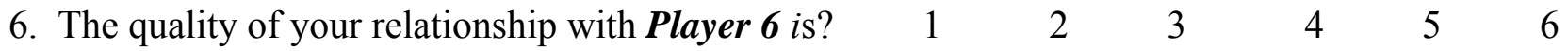

7. The quality of your relationship with Player 7 is? $\quad \begin{array}{llllllll} & 1 & 2 & 3 & 4 & 5 & 6\end{array}$

8. The quality of your relationship with Player 8 is? $\quad \begin{array}{llllllll} & 1 & 2 & 3 & 4 & 5 & 6\end{array}$

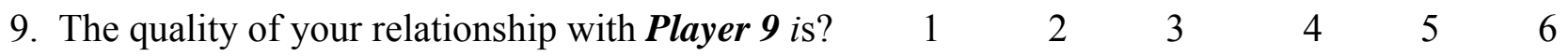

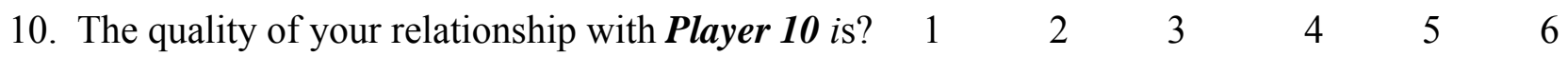



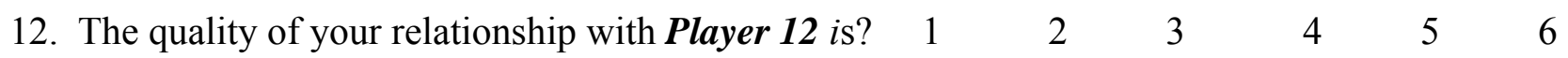

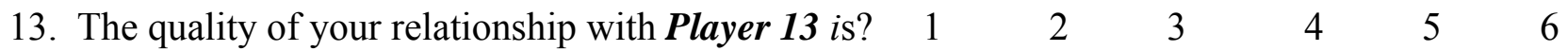

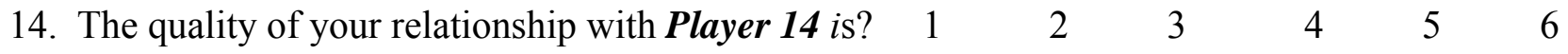

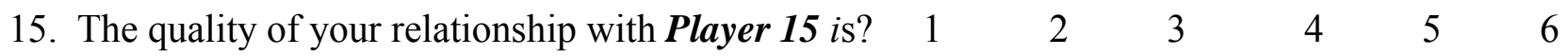

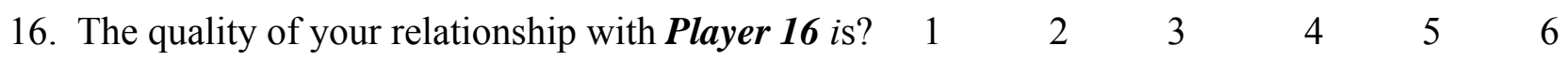

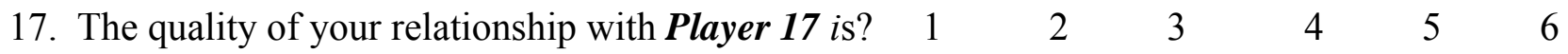

18. The quality of your relationship with Player $\mathbf{1 8}$ is? $\quad 1 \quad \begin{array}{lllllll}2 & 3 & 4 & 5 & 6\end{array}$

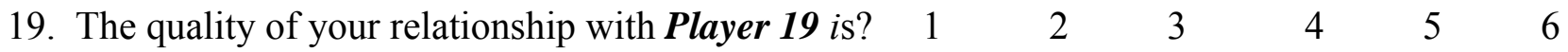

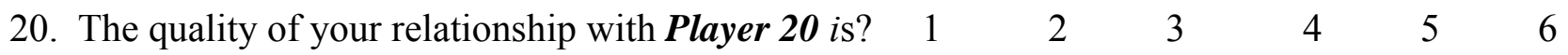


EI, Coach-Athlete Relationships, and Motivation 48

APPENDIX C

ATHLETE DEMOGRAPHIC QUESTIONNAIRE 


\section{ATHLETE DEMOGRAPHIC QUESTIONNAIRE - Page 1}

\section{PART 1: Please tell us a bit about who filled out this survey...}

1. Age in years:

3. What is your class standing? Freshman Sophomore Junior Senior

4. Please state the number of years you have been playing soccer competitively.

5. Please state the number of years and months you have been competing for your current coach in soccer. years, months.

6. How many college games have you started in your playing career?

7. On a scale of 1 to 6 ( 1 being extremely dissatisfied and 6 being extremely satisfied) how satisfied have you been about your college soccer experience?

8. Up to this point of the season your team has a record of: wins, losses, and ties.

PART 2: Please indicate how you view your effectiveness by circling the response that corresponds to your feelings toward each statement ( 1 = Not at all effective to 6 very effective). Please respond as candidly as possible and recall that there are no right or wrong answers.

\section{Not at all effective}

1. How effective is your coach at building a positive relationships $\quad \begin{array}{lllllll}1 & 2 & 3 & 4 & 5 & 6\end{array}$ with you?

2. How effective is your coach at motivating you?

$\begin{array}{llllll}1 & 2 & 3 & 4 & 5 & 6\end{array}$

3. How effective is coach at being 'in tune' with your emotions?

$\begin{array}{llllll}1 & 2 & 3 & 4 & 5 & 6\end{array}$

4. Overall, how would you rate your coach's coaching $\begin{array}{llllll}1 & 2 & 3 & 4 & 5 & 6\end{array}$ effectiveness? 


\section{ATHLETE DEMOGRAPHIC QUESTIONNAIRE - Page 2}

PART 3: Please indicate your answer to the statements below by circling the response that corresponds to your feelings toward each statement. Please respond as candidly as possible and recall that there are no right or wrong answers.

5. The quality of my relationship with my coach $i$ s?

\begin{tabular}{|c|c|c|c|c|c|}
\hline $\begin{array}{l}\text { Very } \\
\text { poor }\end{array}$ & & & & & $\begin{array}{l}\text { Very } \\
\text { strong }\end{array}$ \\
\hline 1 & 2 & 3 & 4 & 5 & 6 \\
\hline
\end{tabular}

6. Up to this point of the season you feel your

Below
expectations
1
team is performing:

\section{Improvement}

Winning

7. As an athlete how do you measure your success:

12

3

Above
expectations
$\quad 6$

8. How does your coach measure your success:

1

23

$3 \quad 4$

$4 \quad 5$

9. Please describe your goals of sport participation below: 
EI, Coach-Athlete Relationships, and Motivation 51

APPENDIX D

MAYER-SALOVEY-CARUSO EMOTIONAL INTELLIGENCE TEST

Purchased from MHS 
EI, Coach-Athlete Relationships, and Motivation 52

\section{MSCEIT}

No paper hard copy of the MSCEIT was used for this study. Check with MHS publisher to obtain paper hard copy. 
EI, Coach-Athlete Relationships, and Motivation 53

APPENDIX E

COACH-ATHLETE RELATIONSHOP QUESTIONNAIRE, ATHLETE VERSION

Reprinted with permission from Jowett. March 2008 


\section{ATHLETE VERSION}

\section{The Coach - Athlete Relationship Questionnaire (CART-Q) Direct}

This questionnaire aims to measure the quality and content of the coach-athlete relationship. Please read carefully the statements below and circle the answer that indicates whether you agree or disagree. There are no right or wrong answers. Please respond to the statements as honest as possible and relevant to how you personally and generally feel with your coach.

\section{Strongly Disagree Moderately Strongly Agree}

$\begin{array}{llllllll}\text { 1. I am close to my coach } & 1 & 2 & 3 & 4 & 5 & 6 & 7 \\ \text { 2. I am committed to my coach } & 1 & 2 & 3 & 4 & 5 & 6 & 7 \\ \text { 3. I like my coach } & 1 & 2 & 3 & 4 & 5 & 6 & 7 \\ \text { 4. When I am coached by my coach, I am at } & 1 & 2 & 3 & 4 & 5 & 6 & 7 \\ & \text { ease }\end{array}$

$\begin{array}{lllllllll}\text { 5. I trust my coach } & 1 & 2 & 3 & 4 & 5 & 6 & 7 \\ \begin{array}{l}\text { 6. I feel that my sport career is promising with my } \\ \text { coach }\end{array} & 1 & 2 & 3 & 4 & 5 & 6 & 7\end{array}$

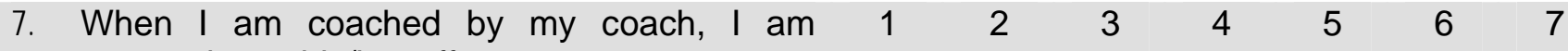 responsive to his/her efforts
8. I respect my coach

$\begin{array}{lllllll}1 & 2 & 3 & 4 & 5 & 6 & 7\end{array}$
9. I appreciate my coach's sacrifices in order to improve performance

1
23

$\begin{array}{lllll}3 & 4 & 5 & 6 & 7\end{array}$

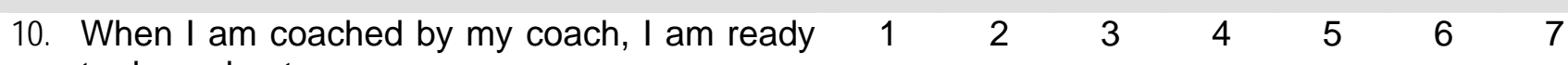
to do my best
11. When I am coac
friendly stance

12

$3 \quad 4 \quad 5$
$6 \quad 7$ 
EI, Coach-Athlete Relationships, and Motivation 55

\section{APPENDIX F}

PERCEPTION OF MOTIVATIONAL CLIMATE IN SPORT QUESTIONNAIRE-2 
Directions: Please read each of the statements below and respond to each in terms of how you view your team. Please respond as honestly as possible and recall that there are no right or wrong answers.

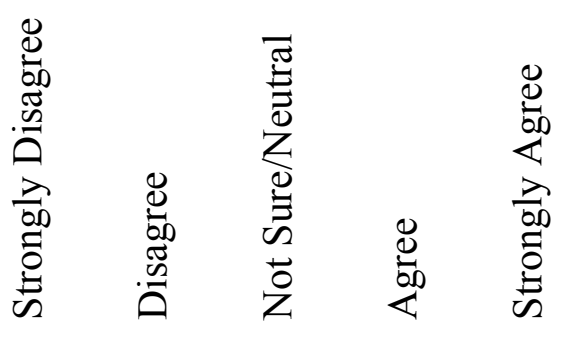

1. On this team, the coach wants us to try new skills.

$\begin{array}{lllll}1 & 2 & 3 & 4 & 5\end{array}$

2. On this team, the coach gets mad when a player makes

$\begin{array}{lllll}1 & 2 & 3 & 4 & 5\end{array}$
a mistake.

3. On this team, the coach gives most of his or her attention to the stars.

4. On this team, each player contributes in some important way.

5. On this team, the coach believes that all of us are crucial to the success of the team.

6. On this team, the coach praises players only when they outplay team-mates.

7. On this team, the coach thinks only the starters contribute to the success of the team.

$\begin{array}{lllll}1 & 2 & 3 & 4 & 5\end{array}$

8. On this team, players feel good when they try their best.

9. On this team, players are taken out of the game for mistakes.

$\begin{array}{lllll}1 & 2 & 3 & 4 & 5\end{array}$

10. On this team, players at all skill levels have an important role on the team.

11. On this team, players help each other learn.

$\begin{array}{lllll}1 & 2 & 3 & 4 & 5\end{array}$

12. On this team, players are encouraged to outplay

1
other players.

13. On this team, the coach has his or her own favorites. 
Directions: Please read each of the statements below and respond to each in terms of how you view your team. Please respond as honestly as possible and recall that there are no right or wrong answers.

14. On this team, coach makes sure players improve skills they're not good at.

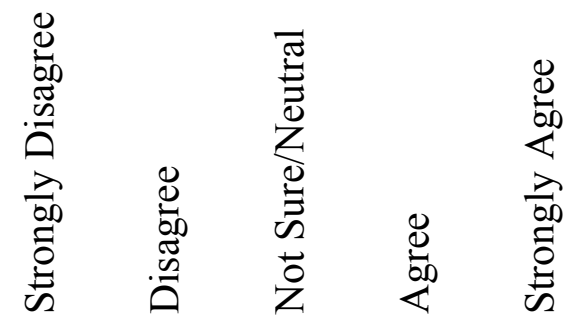

15. On this team, the coach yells at players for messing up. $\quad \begin{array}{lllllll}1 & 2 & 3 & 4 & 5\end{array}$

16. On this team, players feel successful when they improve. $\quad \begin{array}{lllllll}1 & 2 & 3 & 4 & 5\end{array}$

17. On this team, only the players with the best 'stats' $\quad \begin{array}{lllllll}1 & 2 & 3 & 4 & 5\end{array}$ get praise.

18. On this team, players are punished when they make a mistake.

19. On this team, each player has an important role. $\quad \begin{array}{lllllll}1 & 2 & 3 & 4 & 5\end{array}$

20. On this team, trying hard is rewarded. $\quad \begin{array}{lllllll}1 & 2 & 3 & 4 & 5\end{array}$

21. On this team, the coach encourages players to help each $\quad \begin{array}{lllllll}1 & 2 & 3 & 4 & 5\end{array}$ other.

22. On this team, the coach makes it clear who he or she thinks $\quad \begin{array}{lllllll}1 & 2 & 3 & 4 & 5\end{array}$ are the best players.

23. On this team, players are 'psyched' when they do better than their team-mates in a game.

$\begin{array}{lllll}1 & 2 & 3 & 4 & 5\end{array}$

24. On this team, if you want to play in a game you must be one of the best players.

25. On this team, the coach emphasizes always trying your best.

$\begin{array}{lllll}1 & 2 & 3 & 4 & 5\end{array}$


Directions: Please read each of the statements below and respond to each in terms of how you view your team. Please respond as honestly as possible and recall that there are no right or wrong answers.

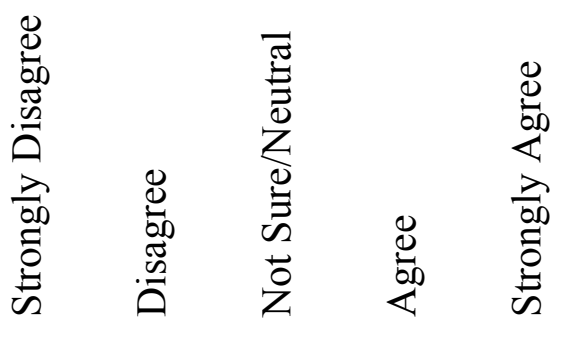

26. On this team, only the top players 'get noticed' by the coach.

27. On the team, players are afraid to make mistakes.

28. On this team, players are encouraged to work on their weaknesses.

$\begin{array}{lllll}1 & 2 & 3 & 4 & 5\end{array}$

29. On this team, the coach favors some players more

1 than others.

$\begin{array}{lllll}1 & 2 & 3 & 4 & 5\end{array}$

30. On this team, the focus is to improve each game/practice.

31. On this team, the players really 'work together' as a team.

$\begin{array}{lllll}1 & 2 & 3 & 4 & 5\end{array}$

32. On the team, each player feels as if they are an important team member.

$\begin{array}{lllll}1 & 2 & 3 & 4 & 5\end{array}$

33. On this team, the players help each other to get better and excel. 
EI, Coach-Athlete Relationships, and Motivation 59

APPENDIX G

STATEMENT OF THE RESEARCH PROBLEM 
The Problem

\section{Statement of the Problem}

The purpose of this research investigation is to examine the relationships between a coach's level of emotional intelligence, the coach-athlete relationships, and the motivational climate of a team. The ultimate goal is to better understand differences between coaches high in EI compared with coaches who are low in EI in their ability to connect to and motivate athletes. Scope of the Study

This study will involve approximately 40 DIII NCAA head men's soccer coaches (all male coaches) and a sub-set of approximately 100 male athletes representing 4 to 6 soccer men's teams. This study will consist of two phases. In Phase I of the study, approximately 40 coaches will be administered an online measure of emotional intelligence (EI) the Mayer-SaloveyCaruso Emotional Intelligence Test (MSCEIT; Mayer, Salovey, \& Caruso, 2002; see Appendix D) and a demographic questionnaire (see Appendix A). Scores of coaches' EI from Phase I will be used to select coaches and athletes for Phase II of this study. Specifically, athletes who are coached by coaches with high EI, as measured by the MSCEIT, and athletes who are coached by coaches with low EI, as measured by the MSCEIT, will be recruited for Phase II of this study. In Phase II athletes will be administered an online measure of the Coach-Athlete Relationship Questionnaire (CART-Q; Appendix E; Jowett \& Ntoumanis, 2004), Perceived Motivational Climate in Sport Questionnaire-2 (PMCSQ-2; Appendix F; Newton et al., 2000), and an athlete demographic questionnaire (see Appendix C).

All coaches will be invited to participate in Phase I. Phase II participation will depend on results of Phase I. Phase II of this study will employ a two-group ("high EI coached athletes” versus "low EI coached athletes"), correlational design. 
The independent variable in Phase II this study will be emotional intelligence level of an athlete's coach as measured by the online version of the Mayer-Salovey-Caruso Emotional Intelligence Test (MSCEIT). Dependent variables in Phase II will be: (1) coach - athlete relationship assessed using the Coach-Athlete Relationship Questionnaire (CART-Q; Appendix E; Jowett \& Ntoumanis, 2004); (2) athletes’ perceived motivational climate assessed using Perceived Motivational Climate in Sport Questionnaire-2 (PMCSQ-2; Appendix F; Newton et al., 2000); (3) athlete's perception of coach's ability to motivate players assessed using the athlete demographic questionnaire (see Appendix C); and (4) athlete's sport participation satisfaction assessed using the athlete demographic questionnaire.

Basic Assumptions

1. Coaches will have sufficient information about their athletes to accurately complete the CART-Q.

2. Athletes will have sufficient information about their coach to accurately complete the CART-Q.

3. MSCEIT, CART-Q, PMCSQ-2 are reliable and valid measure of emotional intelligence and the MSCEIT is pertinent to a sport coaching domain.

4. Enough coaches will participate in Phase I of the study, and that coaches will provide access to their team if selected to participate in Phase II of the study.

5. Coaches will provide access to teams for Phase II of the study.

6. Of the coaches that complete the measure of emotional intelligence, there will be a large enough distribution of coaches' EI scores so teams can be statistically separated into high EI coached athletes and low EI coached athletes groups.

\section{Limitations of the Study}


1. Extraneous variables such as win-loss record may have an impact on the coach-athlete relationship and motivational climate.

2. External ecological validity beyond the sport of soccer.

3. Attrition of coaches from Phase I to Phase II.

\section{Definition of Terms}

Emotional Intelligence is "the ability to perceive accurately, appraise, and express emotions; the ability to access and/or generate feelings that facilitate thought; the ability to understand emotion and emotional knowledge; and the ability to regulate emotions to promote emotional and intellectual growth" (Mayer \& Salovey, 1997, p. 10).

Coach-Athlete Relationship has been conceptualized as a relationship when coaches' and athletes' feelings, thoughts, and behaviors are interdependent. (Jowett \& Meek, 2000). More specifically, Jowett's CAR theory emphasizes how the constructs of Closeness, Commitment and Complementarity influence coach-athlete relational aspects of emotions, cognitions and behavior respectively.

Motivational Climate is the situational motivation structures seen by the athletes as emphasized in a particular setting (Nicholls, 1989). Motivational climate is composed of two goal structures: mastery and performance climate. Mastery climate is a task-involved goal achievement perspective that emphasizes the process of competition and self-improvement through skill development, whereas, performance climate is an ego-involved goal achievement perspective that focuses on the competitive outcome.

\section{Significance of the Study}

Coordinating EI and coaching effectiveness research within sport could help fill the gap in the leadership literature by providing valuable insight into why certain coaches are able to more 
effectively motivate, lead, and foster social attachment with the athletes they coach. Efforts invested in researching EI's role in coaching has the potential to lead to important advancements in the coaching effectiveness literature and training techniques. For example, from an elite athletic perspective, if shown to be linked to a coach's ability to strengthen interpersonal relationships with and motivate players, EI may be a key skill that allows elite coaches to effectively get high levels of emotional commitment and physical effort out of their players on such a consistent basis. Knowledge gained from research on EI and coaching may provide a better understanding of coaching effectiveness and help produce valuable new information that could be integrated into coaching education programs. For example, if EI can be increased in coaches through EI focused coaching education workshops and if EI is linked to a coach's ability to connect to and motivate their players, coaches may be able to directly increase their athletes' overall enjoyment and desire to continue sport participation.

Today, over 35 million children ages 4 through 14 participate in organized youth sports. However, over $70 \%$ of kids drop out of organized youth sports by age 13 (Bigelow, 2006). The main reasons children drop out is pressure from adults, and no longer finding their sport experiences fun. Kids need exercise and the fun and socialization that sport participation provide. In addition, high youth sport dropout rates only exacerbates America's current problems of childhood obesity. Thus, from a recreational athletic perspective, the notion of increasing youth players overall enjoyment of their sport participation by teaching youth coaches how to be more emotionally intelligent could help decrease the high participation dropout rates in US youth sports. Thus, integrating an emotional intelligence training component to coaching education programs, particularly at the youth sport level, could hold the secret to help reduce the current drop out trend in US youth sport. It is important to note that that 
many companies in the healthcare (Evans \& Allen, 2002) and corporate (George, 2000) fields have already incorporated EI into employee training programs as an attempt to develop employees with better interpersonal skills. Thus, the idea of integrating emotional intelligence training component to coaching education programs to potentially increase a coach's ability to build strong relationships with and motivate players is not so farfetched.

In summary, coaches and their athletes, from both professional and recreational levels, could benefit from research that assesses the role EI may play in developing stronger relationships between coaches and players, positive motivational climates, better athletic performances, and more enjoyable athletic experiences. 
EI, Coach-Athlete Relationships, and Motivation 65

APPENDIX H

REVIEW OF LITERATURE 


\section{REVIEW OF LITERATURE}

Research centered on coaching effectiveness suggests being able to effectively lead athletes requires a wide range of skills and abilities. Coaches are expected to fulfill many different roles, that include, but are not limited to the role of the teacher, leader, motivator, the authority figure, and friend. If coaches are going to be successful in all of these roles, they need to have knowledge and skills to meet these expectations. Having only sport playing experience and tactical and technical acumen may not be enough to successfully fulfill all the roles that are required for a coach to successfully lead athletes (Clews \& Gross, 1995; Hoigaard \& Jorgensen, 2007; and Janssen \& Dale, 2002).

Not only do coaches need to fulfill multiple roles, but they also are required to endure a unique set of external pressures and thus need further abilities to handle such pressures. For example, youth coaches need to deal with over-stepping parents and knowing how much of an influence they, as coach, have on a child's psychosocial development. College coaches are carefully monitored by AD's and need to adhere to NCAA rules while boosters demand wins. Professional coaches need to deal with team owners, public scrutiny from the press, multimillionaire contracts, and multimillionaire egos. All levels of coaching come with significant pressures and this is evident from the high turn-over rate in coaching positions. These unique roles and pressures of coaching would be challenging to anyone. To further the challenge, more often than not, coaches generally lack any type of formal education or preparation for these roles (McCallister et al., 2000). Thus, without any formal training there seems to be confusion and inconsistencies about what abilities are required for a coach to successfully lead athletes. 
The critical question then remains not only what abilities allow coaches to effectively lead their athletes, but also equally important how do coaches learn these abilities? Thus, the purpose of this literature review is to explore factors related to coaching effectiveness and to review EI literature in other fields to provide a rationale that, although not researched in this domain, EI might be a useful addition to this line of research and could be among the abilities that define highly successful coaches. The following chapter will review literature in the areas of: a) motivational climate b) coach-athlete relationship; c) emotional intelligence; and, d) summary of review of literature.

\section{Motivational Climate}

One could argue that a central focus of sport participation is to promote skill development and enhance the participants' perceptions of competence, satisfaction, and long-term motivation. Motivational climate, the situational structures seen by the athletes as emphasized in a particular setting, has been linked to critically affecting motivational responses (Nicholls, 1989), quality of relationship with teammates and coaches (Fry \& Newton, 2003), and perceived improvement (Balaguer, Duda \& Crespo, 1996). Motivational climate is composed of two goal structures: mastery and performance climate. Mastery climate is a task-involved goal achievement perspective that emphasizes the process of competition and self-improvement through skill development, whereas, performance climate is an ego-involved goal achievement perspective that focuses on the competitive outcome (Newton et al., 2000). These perspectives represent different manners in which individuals construe their competence and perceive themselves to be successful in achievement contexts (Nicholls, 1989). A large literature base has been established in sport psychology that has supported Nicholls' goal perspective theory within a physical 
domain (see Ntoumanis \& Biddle, 1999 for a detailed review of dispositional and motivational climate research).

In a seminal experiment conducted by Duda and Chi (1989), ego- and task-involving game conditions were created in one-on-one intramural basketball games using American college male students. The study assessed the impact of the two experimental conditions on performance attributions and post-performance ratings of perceived ability basketball players. Athletes in the task-involving condition emphasized individual effort and improvement in techniques. Specifically, in the task-induced condition, participants were asked to judge their performance on their individual effort and improvement. However, in the ego-involving condition, athletes were asked to judge performance on winning and on public recognition of performance. The results showed that, in the ego-involving condition, performance attributions were used to judge the objective outcome (win or loss) but in the task-involving condition, athletes used performance attributions (personal effort, personal ability, opponent's ability, and luck) to judge if performance was perceived as successful or unsuccessful. In the ego-involving condition there was a relationship between perceived competence and objective outcome and in the task-involving condition, perceptions of competence were unrelated to objective success. In the task-involving condition, athletes used subjective criteria to judge the adequacy of their competence. Thus, a task orientation positively relates to a willingness to exert effort.

Summarizing, task-involved individuals experience success when they try hard and improve their skill at an activity. Thus, feelings of competence arise from personal improvement and task mastery through increased effort. Alternatively, ego-involved individuals tend to make judgments about subjective success through social comparison processes. Thus, athletes are concerned about demonstrating more competence then others. Consequently, when ego-involved, 
an athlete feels successful only if his/her performance compares favorably with others or if s/he performs similarly with less effort. Initial assessments of goal orientations were targeted towards the academic setting but several sport specific measures stemmed from this work.

Motivational climate assessment. Initial efforts to assess motivational climate occurred in the educational domain. Ames and Archer (1988) and Nicholls (1989) identified theoretical differences between what they coined as a 'mastery' and a 'performance' climate in the classroom. The differences were based on the degree of social comparison, the rewards, punishments distributed, and the quality of the interpersonal relationships being fostered in each motivational climate. Recent research has tried to draw upon the model developed by Ames and her colleagues (Ames and Archer, 1988) and to determine its utility in differentiating similar dimensions of the motivational climate in the sport domain.

Seifriz and colleagues (1992) developed the Perceived Motivational Climate in Sport Questionnaire (PMCSQ) to assess athletes' perceptions of the motivational climate goal structures created by their coach. Similar to classroom-based research, exploratory factor analysis of the PMCSQ revealed perceived performance (Ego-Involved) climate and a perceived mastery (Task-Involved) as the two major dimensions of the motivational climate operating on the sample of adolescent male basketball teams they used for this study (Seifriz et al., 1992). Results also indicated that the Task-Involved climate athletes perceived that co-operative learning was encouraged by the coach, trying hard and improving were valued by the coach, and every member of the team had an important role to play. However, the Ego- Involved motivational climate players perceived that they were punished when they made a mistake, the coach primarily recognized and reinforced the better players, and intra-team member rivalry was present on the team. 
Although initial testing of the PMCSQ supported its psychometric validity and reliability, several prominent motivation researchers have suggested that the measure could be improved. Specifically, Seifriz et al. (1992) and Walling et al. (1993) proposed that the PMCSQ could be strengthened by conceptualizing the motivational climate in a hierarchical manner with subscales underlying the higher-order Task-Involving and Ego-Involving scales. This suggestion was derived by Ames' initial conceptual framework that viewed task-involving and ego-involving motivational climates as composites of several underlying dimensions or characteristics of the larger environment (Ames and Archer, 1988). Adhering to these suggestions, Newton et al. (2000) expanded the original questionnaire and developed a hierarchical measure of the motivational climate in sport, called the Perceived Motivational Climate in Sport Questionnaire2 (PMCSQ-2). This resulted in a final pool of 42 items, which were then integrated with the 21 items of the original PMCSQ to form the 63-item PMCSQ-2. The PMCSQ-2 was designed to assess players' perceptions of the degree to which their team's motivational climate is characterized in terms of two higher order dimensions (task or ego involving climate) which are composed of 6 underlying characteristics. These characteristics are labeled Effort/ Improvement, Important Role, Cooperative Learning, Intra-Team Member Rivalry, Unequal Recognition, and Punishment for Mistakes. Work on the PMCSQ-2 has found the assessment has adequate internal reliability and factorial validity (Newton et al., 2000; Reinboth \& Duda, 2006) See Chapter 3 of this manuscript for detailed overview of the PMCSQ-2.

Cronbach's coefficient alphas were calculated for each subscale and the proposed higher-order Task-Involving and Ego-Involving scales test internal consistency. Both higherorder scales demonstrated adequate internal consistency (Task-Involving climate, $\alpha=0.87$; EgoInvolving climate, $\alpha=0.89$ ). The Task-Involving motivational climate subscales of 
effort/Improvement $(\alpha=0.83)$ and Important Role $(\alpha=0.77)$ exhibited adequate consistency but the Cooperative Learning subscale $(\alpha=0.66)$ possessed marginally acceptable internal consistency. Similarly, the Ego-Involving motivational climate subscales of Unequal Recognition $(\alpha=0.93)$ and Punishment for Mistakes $(\alpha=0.80)$ exhibited adequate consistency but the Intra-Team Member Rivalry subscale $(\alpha=0.66)$ possessed marginally acceptable internal consistency. Because of the adequate internal consistency and reliability scores and common use across numerous sport sub-domains, the PMCSQ-2 has been established as an accepted sport specific measure of perceived motivational climate (Newton et al., 2000; Reinboth \& Duda, 2006).

Influences on and benefits of a positive motivational climate. The athlete's goal orientations and perceptions of the motivational climate have been found to predict satisfaction with practices, favorable attitudes toward winning (Ntoumanis \& Biddle, 1999), quality of relationship with teammates and coaches (Fry \& Newton, 2003), skill development (Theeboom et al., 1995), perceived improvement, satisfaction with instruction, degree of preference for the coach (Balaguer, Duda \& Crespo, 1996) and perceptions of group task-involved goal orientation, collective efficacy, and social cohesion (Heuze, Sarrazin, Masiero, Raimbault, \& Thomas, 2006). Research conducted by Nicholls (1984) revealed that an ego-involved orientation would lead to maladaptive motivational responses such as low effort and lack of commitment and persistence, whereas a task-involved mastery focused approach would be associated with adaptive motivational responses such as increased effort, commitment and persistence in achievement settings. From Nicholls work, it can be speculated that a positive motivational climate is one that is mastery focused and integrates a task-involved goal orientation. A basic premise of Nicholls' (1989) perspective on achievement goal theory hinges on the belief that goal orientations are 
orthogonal, and thus one can be high or low in either, or both. This notion has been supported by sport specific research conducted by Roberts, Treasure, and Kavussanu (1997). Interestingly, elite athlete's show a unique orthogonal motivational goal orientations.

For example, Pensgaard and Roberts (2002) conducted a qualitative study that provided in depth structured interviews of seven elite athletes. Importantly, the participants in this study were a highly elite group with very high scores on both the ego and task goal dimensions, supporting the prior work by Hardy (1997) that most elite athletes are high in both ego and taskinvolved dimensions. In addition to providing further support that the goal orientations are orthogonal, this study emphasize the potential role a coach plays on establishing a motivational climate and influencing athletes' goal orientations.

Expanding on the role the coach plays in motivational climate Balaguer, Duda, and Crespo (1999) conducted a study that examined the relationship of the perceived motivational climate created by the coach and athlete's perceived improvement in performance, satisfaction with recent performance and training provided by coach. Ratings of their coach compared to an ideal coach, and the importance of the coach with respect to that athlete's learning and improvement were used as measures. Using a sample of 216 youth tennis players ranging from intermediate to advanced skill, this study revealed when the environment created by the coach was perceived as more task-involving, athletes felt that they were improving more in the physical and psychological facets of their game. Youth completed Spanish versions of the Task and Ego Orientation in Sport Questionnaire (TEOSQ; Duda \& Whitehead, 1998) and the PMCSQ-2 to assess goal orientation and motivational climate respectively and completed items assessing perceived improvement specific to tennis, satisfaction, and coach ratings. The tennis players' evaluation of their personal level of improvement in technical, tactical, physical, and 
psychological aspects of their game was evaluated on a 7-point Likert scale ranging from $1=$ "I have gotten worse" to 7="I have gotten much better." The athlete's level of satisfaction was measured by a 7-point Likert scale ranging from 1= "very dissatisfied" to 7= "very satisfied" for results this year, level of play, and the coach. Lastly, each athlete's opinion of their coach was rated on two items. First, whether his/her current coach is like the one the athlete would prefer to have (responses were provided on a 5-point Likert scale ranging from $1=$ " doesn't coincide at all with coach I would like to have" to 7= "is my ideal coach") and second, the perceived importance of the coach in regard to that athlete's learning and improvement (response were provided on a 5-point Likert scale ranging from 1= "not important all" to 5= "extremely important.) If the environment created by the coach was deemed more task-involving, the athletes were more satisfied with the amount of teaching and personalized treatment they were receiving from the coach. This finding is consistent with another recent work conducted by Balaguer and colleagues (1996) that suggested that athletes feel that their coaches engage in more teaching and instruction and provided greater social support when they perceive the motivational as more task-involving. In addition, when athletes perceived the climate to be more task-involving (and especially less ego-evolving), they reported that their current coach was closer to their "ideal" coach. However, it is important to note that perceptions of motivational climate and athlete's goal orientations accounted for only a small amount of variance in performance improvement $\left(\mathrm{R}^{2}=.01-.07\right)$ and reported satisfaction with match results and personal level of play $\left(\mathrm{R}^{2}=.05-.06\right)$. Thus, it appears that other factors besides athletes' dispositional and coach emphasized goal orientations influence self-report ratings of performance and satisfaction with competitive outcomes and play. As a whole this study's 
findings are in line with previous sport research on goal perspective theory and provide further support that regarding the motivational advantageous of a task-involving climate.

Within this same vein, Fry and Newton (2003) utilized Nicholls' (1989) goal perspective theory to examine the extent to which young tennis players' goal orientations and perceptions of the motivational climate predict the quality of relationships they share with tennis coaches and peers in a tennis program. This hypothesis stems from Nicholls' theory that task orientation and perceptions of task-involving climate would be more likely to elicit positive interactions among athletes and coaches due to the emphasis on personal effort and improvement compared to social comparisons. A total of 167 youth tennis players from grant sponsored programs across the US completed questionnaires assessing: demographic information, goal orientations, perceived motivational climate, attitudes regarding sportpersonship, tennis, their instructor, and their fellow players. The tennis programs from which participants were recruited target urban youngsters of low socioeconomic status. The participants mean age was 14.05 years. The Task and Ego Orientation in Sport Questionnaire (TEOSQ; Duda \& Whitehead, 1998) was used to measure athlete's goal orientations. The PMCSQ-2 was used to measure the perceived motivational climate. Seven items were included to assess athletes' attitudes towards tennis, their instructor, and their fellow players. These items were adopted from a Smith and Smoll study (1979) that assessed similar question in a study on youth baseball. The only changes that were made to Smith and Smoll's items were in replacing terms "baseball" to "tennis" and "coach" to "tennis pro”. Mean scale scores were computed for each construct. Questions assessing attitudes towards tennis included "How much do you like tennis?" and "DO you like tennis more or less than you did at the beginning of the season?" Questions assessing attitudes towards instructor included "How much do you like playing for your tennis pro?"; "How much would you like to 
have the same tennis pro again next year?" and "How much do you like your tennis pro?".

Questions assessing attitudes towards fellow players included "How well did the players in your program get along?" and "How much did you like the other players in your program?" Athletes responded to each question using a 5-point Likert scale ranging from 1 "Not at all" to 5 "a lot". Coefficient alpha for the three-item measure of players' attitudes towards their coach revealed the scale to be internally consistent $(\alpha=.86)$. However, results from the two additional assessments (attitudes towards tennis and attitudes towards players) should be interpreted with caution due to concerns about reliability. To explore how goal orientations and motivational climate were related to players' attitudes simple Pearson correlation coefficients were calculated. Results revealed that the more players perceived that their tennis program was task-involving their attitudes towards their tennis instructors were more positive. Thus, an athlete's perception of a task-involving motivational climate has a positive correlation with also having positive attitudes towards their coach $(r=.51)$. Specifically, when athletes perceived a highly taskinvolving climate they indicated they liked their tennis instructors, enjoyed playing for them, and want to have the same tennis instructor the following year. Similarly, when athletes perceived a highly task-involving climate they indicated more positive attitudes towards their peers than athletes who perceived an ego-involving climate.

Providing further support of such a relationship is Smith and colleagues' $(1990 ; 1991)$ seminal work with Coaching Behavior Assessment System. Unfortunately, these studies didn't directly measure goal orientations or motivational climate. However, they have identified a profile of coaching behaviors that significantly overlaps with the essence of task orientation and task-involving climate. Specifically, study results suggest that if coaches engage frequently in 
encouragement and technically instruction with infrequent use of punishment, then athletes report having more positive experience with their sport, peers, and coaches.

Both the Balaguer, Duda, and Crespo (1999) and Fry and Newton (2003) articles support the theory that an athlete's task or ego-involved goal perspective while engaging in an achievement activity is a function of their dispositional tendencies (e.g. the degree of task and ego orientation) and the goal structure emphasized by the coach. It is reasonable to assume that it is easier to modify environmental goal structures in contrast to the dispositional goal perspectives. Thus, this highlights the responsibility and important influence a coach has when establishing a positive, task-involving, motivational climate for his/her team. In the aforementioned study by Pensgaard and Roberts (2002) that assessed elite athlete's goal perspectives using a qualitative approach, several of the interviewed athletes placed great importance on the team climate and the climate created by the coach. The fact that the climate is so important even with elite athletes is encouraging because, as Whitehead et al. (1997) have argued, the climate is easier to manipulate than the individual goal dispositions. Even athletes who have won World Championships and Olympic Medals emphasize that the role of the coach is important in fostering a nurturing motivational climate. With the main architect of the motivational climate of a sport team being the coach and because the coach has the power to motivate athletes by utilizing a supportive task-involved coaching style (e.g. provides higher level of feedback, valuing effort and improvement not just outcomes, and uses positive interactions that fosters trust, perceptions of improvement, and confidence in athletes), it can be reasonably assumed that a task-involved motivational climate has relevance to the quality of the coach-athlete relationship.

\section{Coach-Athlete Relationship}


Because of the potential benefits on youth and professional sport, the relationship that develops between an athlete and coach has received moderate scientific research attention that has lead to a diversity of theories. Some theories have a negative perspective of the coachathlete relationship and characterize it as a relationship built solely on utility. Using this perspective, the coach athlete relationship is seen as a lesser form of a human relationship, one that both parties only get out of it what they can (Drewe, 2002, as cited in Jowett, 2007). Alternatively, Neale and Tutko (1975, as cited in Jowett, 2007) suggest that although a coachathlete relationship evolves over time, at its core is a relationship similar to that of a parent and child and thus the relationship contains elements of trust, nurturing, and responsiveness to the needs of the athlete. Building on this theory, Jowett and colleagues (2004) argue that although intuitively appealing, characterizing the coach-athlete relationship as similar to that of a parent and child is not accurate because the asymmetric power and authority inherent in the parent-child relationship does not accurately represent the coach-athlete relationship. Thus, Jowett suggests (Jowett and Ntoumanis, 2004) that the coach-athlete relationship is grounded in a more positive, symbiotic, interdependent connection.

Regardless if one uses a gritty authoritarian Bob Knight coaching style or a warm democratic Pete Carroll coaching style, nearly all successful coaches are successful at building strong interdependent relationships with their players as is suggested by Jowett's theory. Thus, research centered on how and what abilities elite coaches use to successfully build strong coachathlete relationships would seem highly pertinent to coaching education and sport psychology research.

Overall, this diversity of perspectives has fueled an increase in efforts to systematically study the coach-athlete relationship and elucidate how successful coaches build relationships 
with their players. As result, theoretically grounded approaches to explain the coach-athlete relationship and subsequent assessments to measure this multifaceted relationship have been developed.

Coach-athlete relationship assessment. Most of the research developing assessments of the coach-athlete relationship evolved from interpersonal relationship assessments developed within business fields. In the 1950's Schultz developed the Fundamental Interpersonal Relations Orientation theory, (FIRO; 1966, as cited in Kramer, 1967), and the subsequent Fundamental Interpersonal Relations Orientation-Behavior scale (FIRO-B; Schultz, 1966, as cited in Kramer, 1967). Both were originally used in Industrial/Organizational psychology. The FIRO theory involves the compatibility of needs and behaviors between the leader and each individual follower (Schultz, 1966, as cited in Kramer, 1967). This theory suggests that there are three types of behaviors that people have a need to express and receive in their relationship with others: inclusion, control, and affection (Schultz, 1966, as cited in Kramer, 1967). Inclusion is defined as how much one wants others to be involved in his/her activities or wants to be involved in others' activities. Control involves how much one desires to be controlled or wants to control others, and affection is defined as how much one initiates or desires others to initiate close personal interactions. The original purpose of the FIRO-B was to measure these three types of behaviors in how an individual behaves toward others and wants others to behave toward him/her with 54 questions. However, checks of validity and reliability on the original measure suggest problematic psychometric properties. In addition, although the FIRO theory of leadership could be applied to sport, a downfall was it was not sport specific.

As a result, Chelladurai and Saleh (1978) developed the Multidimensional Model of Sport Leadership to help conceptualize leadership as a complex, interactional process, specific to 
sport. The Model assumes that the participants' satisfaction and performance are influenced by the leader's actual behaviors. The leader's actual behaviors are influenced by what behaviors are required by the situation and the athletes' preferred leader behaviors. Thus, optimal performance and satisfaction of the athletes is achieved when the leader's required, actual, and preferred behaviors are consistent. Challadurai and Saleh's Multidimensional Model of Sport Leadership lead to the development of the Leadership Scale for Sport (LSS; Chelladurai \& Saleh, 1980). The LSS is structured around five subscales of coaching behavior: Training and Instruction, Democratic Behavior, Autocratic Behavior, Social Support, and Positive Feedback. The questionnaire consists of 40 items that individuals respond to on a five point scale (i.e. Always, Often (75\%), Occasionally (50\%), Seldom (25\%), and Never). The LSS has shown strong factorial, content, and criterion-referenced validity (Chelladurai \& Saleh, 1980).

Interestingly, the FIRO-B and the LSS were compared to identify the best measure for coach athlete relationships. Several benefits to using the LSS over the FIRO-B were found. The study suggests that the LSS is coach and athlete specific meaning it allows athletes to assess their own coaches, not coaches in general, and focuses on specific coaching behaviors instead of global behaviors. A second advantage of the LSS is that it provides perceptions of coaches' behaviors from the view of the athlete, whereas the FIRO-B only deals with athletes' preferences and perceptions of the coaches. However, Wylleman (2000) criticized the LSS because it only defined interpersonal behaviors by leaders in terms of task-oriented or task-centered behaviors, thus neglecting the relationship or socio-emotional oriented behaviors between coach, parents, and athlete. These researchers believed there was a gap in the research because no previous assessment assessed athletes' perceptions of the relationship oriented behaviors of the dyadic parents-coaches, players-coaches, players-parents relationships. As a result, Wylleman and 
colleagues developed the Sport Interpersonal Relationships Questionnaire (SIRQ), as an alternative to the LSS.

The SIRQ has three versions, one for each of the three dyads in the athletic triangle, athlete-coach, athlete-parent, and parent-coach, SIRQ-AC, SIRQ-AP, and SIRQ-APC respectively (Wylleman, 1995 as cited in Wylleman, 2000). Each SIRQ consists of 80 items and addresses the bi-directional nature of the relationship with 40 questions assessing the athlete's point of view about he/she relates toward the coach and another 40 questions assessing how the coach relates to the athlete. Athletes rate their perceptions on a 5-point scale from 1 (never) to 5 (always). Eight dimensions are included in the instrument: dominance, kindness, caring behavior, dependency, inferiority, aloofness, aggressiveness, and independence (Wylleman, De Knop, Vanden Auweele, \& Sloore, 1994).

An assessment of psychometric properties of the SIRQ was conducted (Wylleman, De Knop, Vanden Auweele, \& Sloore, 1997). Internal consistency scores were shown to be moderate with alpha's no lower than 0.62 and most above 0.70 . Competitive trait anxiety was used to support the divergent validity of the scale, and the SIRQ-AC was found to relate well to the LSS, establishing convergent validity. Test-retest reliability was stable with most scores having a $r>0.60$ over a 4 -week period. Thus, the SIRQ seems to be a valid and reliable means to measure the content of important dyadic relationships in sport by examining socio-emotional interpersonal behaviors and allows for information about perceptions of actual behavior and preferred behavior. It is important to note, that the aforementioned Wylleman et al. (1997) study is one of the only psychometric assessments of the SIRQ. In addition, not many researchers have used this instrument in their studies, so further psychometric properties have only been conducted on select populations (e.g. youth, individual sports, European athletes). As a result, 
research should be extended to other populations in order to more appropriately assess the psychometric strength of this instrument. Recently a new conceptualization of the Coach-Athlete relationship has been gaining attention in sport research literature.

Kelley et al. (1983) define an interpersonal relationship as the situation in which two people's emotions, thoughts and behaviors are interconnected. Thus, drawing on a more emotionally rooted, symbiotic perspective of interpersonal relationships, Jowett and Meek (2000) developed a new coach-athlete relationship theory. A series of qualitative and quantitative studies have been conducted giving rise to and The 3 Cs Model of the coach-athlete relationship (Jowett, 2003; Jowett \& Cockerill, 2003; Jowett \& Meek, 2000). Thus, this theory emphasizes how the constructs of Closeness, Commitment and Complementarity influence coach-athlete relational aspects of emotions, cognitions and behavior respectively.

"Closeness" refers to the emotional aspect in the dyad and is reflected by feelings such as liking, trust, or respect (Jowett, 2002). For example, applying Argyle's (1994 as cited in Jowett, 2002) definition of "liking," the ability to disclose and exchange information freely, to a sporting context, Jowett suggests a coach-athlete relationship that is high in "closeness" will have a coach and athlete who will be able to communicate freely. In addition, trust, defined as the confidence that one individual has in another, also facilitates freely communicating each parties' needs and concerns which in turn leads to effective problem solving. Otherwise, if trust is lacking in a coach-athlete relationship, then performance may be negatively affected as suggested by research conducted by Gould, Guinan, Greenleaf, Medbery, and Peterson (1999). Lastly, respect is another important factor of "Closeness" in Jowett's model because respect indicates unconditional acceptance in the relationship of an individual's position in the dyad (Jowett, 2002). 
"Commitment" is defined by Jowett (2002) as the intention of an individual to maintain an interpersonal relationship. Thus, in the coach-athlete relationship, commitment is defined as the coach's and athlete's intent to maintain their relationship as a "working partnership." With this definition in place, any accommodations or compromises made by either side to counteract any negative impacts made on the relationship by the other party can be measured as "commitment" because if these accommodations/compromises were not made then the working partnership would collapse. The final, behavioral aspect of interpersonal relationships in the 3 C's Model of the coach-athlete relationship is "Complementarity".

Built from the traditional meaning of the term "to complement", Complementarity is reflected in the coach and athlete's actions of cooperation. Cooperative relations include reciprocal behaviors where, for example, a coach instructs while the athlete follows instructions. Thus, the coach and athlete both exhibit a friendly attitude towards one another in training and competition and if this occurs, then the relationship will progress in a positive manner (Jowett, 2002). In summary, Jowett's 3 C's Model suggests coaches and athletes are interdependent in terms of Closeness, Commitment, and Complementarity. According to the model a coachathlete relationship that is interdependent exhibits high-levels of trusts and respect; mutual desires to remain committed and attached to each other in the future; and behave in responsive, friendly, and easy going manners. In contrast, a coach-athlete relationship that is less interdependent exhibits a lack of mutual respect and trust; a lack of interest in maintaining the relationship in the future; and/or a lack cooperative behaviors in the sport domain (Jowett, 2002).

Jowett and Ntoumanis (2004) developed the Coach-Athlete Relationship Questionnaire (CART-Q) as a way to assess the quality of the coach-athlete relationship and the degree to which the coach and the athlete are interdependent, as defined by the 3 C's Model. It is a 11-item 
self-report questionnaire with two versions available: one for a coach's relationship with a player and one for a player's relationship with a coach. Participants respond on a 7point Likert-type scale ranging from "Strongly Agree" to "Strongly Disagree". It measures the intensity of a coach's and athlete's levels of Closeness (e.g., "if I respect my coach”), Commitment (e.g., "I am committed to my coach") and Complementarity (e.g., "When I coach my athlete, I am responsive"). The CART-Q has been found to be valid and reliable measure of the coach-athlete relationship. For a more in depth analysis of the CART-Q's psychometrics please refer to Chapter 3 of this document.

Influences on and benefits of a strong coach-athlete relationship. Satisfaction, enjoyment, self-confidence, and athletic performance are a few variables on which coaches and the dynamic of the coach-athlete relationship has been suggested to impact athletes. In addition, coaches are often viewed by athletes as influential figures. For example, Jowett and Cockerill (2003) examined the interpersonal relationships of 12 Olympic medalists and found that these athletes perceived their coach as a close friend, or as a father- or mother-figure. Furthermore, it has been suggested that the coach-athlete relationship can provide nurturing support during difficult times (e.g. injury, slumps, burn out, disqualification from a major competition) and transitions (e.g. college graduation, professional retirement; Jowett, 2005). Thus, it can be argued that the relationship between coach and athlete is at the core of successful sport training and not only greatly impacts an athlete's sport performance and but also non-sport life.

A good coach-athlete relationship has been correlated with an increase in positive emotions, motivation, satisfaction, and an overall positive experience by both the athlete and coach (Bortoli et al., 1995). More specifically, an athlete's sport participation enjoyment is a key variable that coaches can influence. For example, in a study conducted by Martin et al. (2001) 
$58 \%$ of the variance in athletes' level of enjoyment and participation motivation was explained by the athletes' perceptions of the quality of the athlete-coach relationship. Scanlan and Lewthwaite (1986) tracked youth wrestlers throughout one season and found that enjoyment was predicted by a number of variables including positive adult interactions and involvement. More specifically, this study revealed that regardless of past athletic history or success, coaches can have a direct effect on children/youth's sport enjoyment, by providing positive social evaluations, being positively involved in the child's sport experience, and by giving recognition for achievements. Interestingly, Schliesman (1987) studied two aspects of athletes' coaching satisfaction; satisfaction with general leadership and satisfaction with specific coaching behaviors. Specifically, this study assessed the preferences for, perceptions of, and the discrepancy between actual coaching behaviors for each participant. Participants consisted of male track and field college athletes. Results concluded that participants reported greater general satisfaction with leadership when they perceived democratic and social support from their coaches. When it came to satisfaction of specific coaching behaviors, the strongest relationships were between low discrepancy scores in training and instruction, social support, and positive feedback. Overall, social support seemed to influence satisfaction the most. The key findings to draw from this study are when examining athlete satisfaction and overall experience, the congruency between perceived and preferred leadership behavior is a key factor.

It is important to note that the aforementioned studies utilized a correlational approach and thus are limited because results cannot support cause and effect relationships. However, Fox, Rejeski, and Gauvin (2000) used an experimental design to assess how an athlete's sport participation enjoyment may be influenced by coaching behaviors. In this study, approximately 100 college students participated in a single session step aerobics class where the instructors led 
either an "enriched" or "bland" series of interactions. Participants in the enriched condition reported higher enjoyment levels than in the bland class.

Lastly, research suggests confidence increases effort and motivation (Allen \& Howe, 1998; Weinberg, Yukelson, \& Jackson, 1980) momentum shifts (Miller \& Weinberg, 1991; Shaw, Dzewaltowski, \& McElroy, 1992), and ultimately performance (Vealey, 2001). Thus, these studies suggest coaches who can positively influence their players' self-confidence level can in turn positively affect an athlete's performance, particularly in youth athletes, who are greatly influenced by significant adult figures.

In summary, these research efforts reveal the multifaceted nature of the coach-athlete relationship and suggest just how integral of a role this relationship plays in affecting an athlete's performance and emotional well-being. Some coaches were born with or have developed higher knowledge, experience, and skills to successfully fulfill athletes' needs for development and growth as sport performers and human beings. The idea that a coach can affect an athlete's performance in both negative and positive ways depending on their skill-set gets back to the core question of this paper; what does it take to be a successful coach? As previously mentioned, several investigators have been vocal in their support for the use of the new construct of emotional intelligence as a line of research that may help distinguish highly successful coaches (that the author hypothesizes build good relationships and better motivational climates) from less successful coaches (McCann, 1999; Meyer \& Fletcher, 2007; Zizzi et al., 2003).

\section{Emotional Intelligence}

When early psychologists began to study intelligence, the focus was centered on cognitive aspects, such as memory and problem solving. This evolved into the construct of general (cognitive) intelligence and the traditional measure of intelligence, IQ. However, other 
researchers were vocal about a multiple-intelligence construct of intelligence. In the early 1980's, Gardner (1983) introduced the idea of "intrapersonal" and "interpersonal" intelligences and suggested they were as important as traditional IQ to predicating real-world success. Bolstering this claim, research conducted by Sternberg and colleagues (2000) suggested that general (cognitive) intelligence predicts some aspects of academic and occupational status but accounts for a lowly $20 \%-25 \%$ of the variance in real-world success. Thus, the rise of multidimensional theories of intelligence and the realization that cognitive intelligence may only partially predicate real-world success stimulated researchers to further explore other types of intelligence. Recently, emotional intelligence has been the focus of much research that strives to explain alternatives to the traditional cognitive intelligence constructs and is hypothesized as a learned ability that differentiates successful performers in a variety of fields. Many researchers have attempted to define the term emotional intelligence (Goleman, 1995; Mayer \& Solvey, 1997). Several instruments have been developed to assess the viability of the emotional intelligence construct in predicting various outcomes. There are two main models of EI each with several independently designed measures. One model that suggests that innate competencies drive EI (Mixed model) and a second model that suggest certain learned skills/abilities make up EI (Ability model). Due to the numerous definitions and measurements of emotional intelligence, it is critical to clarify the pros and cons of each model.

Models of EI and assessment approaches. Goleman and colleagues formulated the Mixed Model of EI that defines emotional intelligence as a competency that entails selfawareness, self-management, social awareness, and social skills used at appropriate times in effective ways (1995). Thus, EI is conceptualized broadly as being determined by mental abilities. Based on this definition, Goleman established the Emotional Competence Inventory 
(ECI) to measure EI. This is a 110 item self-report measure of 20 behavioral competencies within four domains (-awareness, self-management, social awareness, and social skills). Both the validity and reliability of this instrument have been called into question including the findings that that the measured competencies share considerable overlap with Big Five Personality traits (Conte, 2005; Meyer \& Fletcher, 2007). Thus, the ECI suggests that personality traits influence EI and this makes it difficult to differentiate between EI and various personality constructs. Consequently, if EI is determined by personality, then it is a predetermined trait and this contradicts claims that EI is a learnable, improvable group of skills. For these reasons, Goleman's definition and its subsequent ECI measure of EI is not recommended for conceptualizing EI. For a more detailed analysis of the Mixed Model and the validity and reliability of the ECI please see work conducted by Conte (2005) and Meyer and Fletcher (2007). Because of problems with the Mixed Model's definition and psychometrics, several researchers established an alternative model of EI.

The Ability Model is defined exclusively as a skill that is malleable and can be learned and improved. Thus, Salovey and Mayer believe there is no trait or personality component of EI. In Salovey and Mayer's (1990) seminal work on this topic, they defined EI as a: ...set of skills hypothesized to contribute to the accurate appraisal and expression of emotion in oneself and in others, the effective regulation of emotion in self and others and the use of feelings to motivate, plan and achieve in one's life (p. 185).

Using the aforementioned definition, Salovey and Mayer (1997) further conceptualized their ability model asserting that EI consisted of four main skills or branches. The most recent and accepted definition of the Ability model of EI is now 
“...the ability to perceive accurately, appraise, and express emotions; the ability to access and/or generate feelings that facilitate thought; the ability to understand emotion and emotional knowledge; and the ability to regulate emotions to promote emotional and intellectual growth" (Mayer \& Salovey, 1997, p. 10).

The four branches include Perception and Expression of Emotion (Branch 1), Assimilation of Emotion into Thought (Branch 2), Understanding/Analyzing Emotion (Branch 3), and Regulation of Emotion (Branch 4). First, Perception and Expression of Emotion (Branch 1) consists of the ability to recognize and express one's physical states, feelings, and thoughts in self and others This includes the capacity to recognize emotional cues in others' non-verbal facial and postural expressions and express emotion in their own face, voice, and body language. Second, Assimilation of Emotion into Thought (Branch 2) includes the ability to use one's emotions to prioritize thinking in beneficial ways. It has been hypothesized that Branch 2 is a part of intelligence involved in developing knowledge about experiences and how the link between emotions and thinking can direct one's planning. Third, Understanding/Analyzing Emotion (Branch 3) is the ability to label emotions and understand thoughts associated with shifts of emotions. Lastly, Regulation of Emotion (Branch 4) consists of the ability to regulate emotions mindfully so as to nurture emotional and intellectual growth. As previously stated, this is the most advanced emotional skill that is involved in managing emotions within the context of an individual's goals, self-knowledge, and social awareness. Thus, EI includes the ability to structure "emotional sophistication" into four branches: perception and expression of emotion, assimilating emotion in thought, understanding and analyzing emotion, regulation of emotion. It is important to note that developmentally these branches are hierarchical. That is to say, the four 
branches progress incrementally from lower level emotional skills to higher level emotional skills. For example, the ability to monitor emotions in oneself and others and the ability to manage emotions in oneself and others are higher functioning and psychologically more complex abilities of EI (Mayer \& Salovey, 1997). In addition, an individual couldn't develop the ability to regulate emotions without first developing perception of emotions and assimilation of those emotions into thought.

The two assessment inventories developed to measure the Ability model of EI are the Multi-Factor Emotional Intelligence Scale (MEIS: Mayer, Caruso, \& Salovey. 1999) and the Mayer-Salovery-Caruso Emotional Intelligence Test (MSCEIT: Mayer, Salovey, \& Caruso, 2002). The MEIS was developed first and consists of 402 items and four branches. Considering how long this measure took to complete (on average $<2$ hours) and questionable reliability coefficients (Conte, 2005; Meyer \& Fletcher, 2007), the MSCEIT was developed.

The MSCEIT is a 141-item scale designed to measure the four branches of EI. Now in its second version (Mayer, Salovey, Caruso, \& Sitarenios, 2003), the MSCIET provides a total score and four branch score. It can either be completed via pencil/paper booklet or on-line and the correlation of response frequencies between these techniques are very high $(r=.98)$ (Mayer et al., 2003). Factor analysis calculations provide support that the MSCEIT has a four factor structure consistent with the four branch definition (Brackett \& Mayer, 2003). Further analysis suggests a lack of convergence between the MSCEIT and self-report EIS (Mixed-model) measures. In addition, the MSCEIT appears to show appropriate discriminate validity from measures of analytic intelligence and many personality constructs (Brackett \& Salovey, 2006; Mayer et al., 2003). Thus, EI as measured by the MSCEIT seems to be an independent intelligence separate from cognitive intelligence that is distinct from personality traits. 
It is important to note that the scope of this paper is not to analyze and critique the reliability, validity, or usability of each of these instruments in detail. With that said, there is a need for further assessment of EI instruments because few independent peer-reviewed critiques have been published. Meyer and Zizzi (2007) have contributed one of the only independent critical reviews of the numerous EI instruments' validity and reliability as it relates to sport. They argue by developing and using so many different EI measures, research results are very difficult to compare across studies. Similarly, Meyer and Fletcher's (2007) calling for a move away from the use of different definitions, theoretical models, and assessments of EI to the use of a singular definition, conceptual frame-work, and instrument should be applauded. Although unlikely to happen, developing one well established EI measure may be the only means to clarify rather than confuse potential links between EI and sport.

Lastly, it is important to note that the aforementioned EI instruments were develop for use within corporate environments and have just recently been applied to performance in sport psychology (Jones, 2002; Zizzi et al., 2003; Perlini \& Halverson, 2006). There are no EI instruments to date that are specific to sport. This raises questions over statistical validity. For example, can any of the current non-sport specific EI instruments even be used to accurately measure EI within a sport domain? Can EI studies on non-sport fields, such as business leadership effectiveness, be generalized to sport psychology domains, such as coaching effectiveness? If further work on elucidating the role EI plays in sport is to be conducted, then these concerns highlight the need for establishing a sport specific measure of EI. In the end, the aforementioned concerns over ever being able to accurately define and measure the construct of EI raise the questions how Emotional Intelligence may be relevant to sport and coaching domains. 
As previously stated, there is a wealth of research devoted to EI and leadership within business and health-care domains but few studies on EI and sport and no studies of EI and coaching have been conducted. However, EI literature from the business and health care domains relates to coaching in sport and may be useful in elucidating what factors, other than cognitive intelligence, contribute to being a successful coach. For example, research from nonsport domains that EI affects a leader's ability to build strong interpersonal relationships and motivate followers (e.g. Brackett et al., 2003; Palmer et al., 2000; Salovey et al., 2002; Weinberg $\&$ McDermott, 2002). In the following sections, an overview of EI research on Interpersonal relationships and motivation from the fields of business and health-care will be presented in an effort to identity potential links to EI, sport, and coaching. This will be followed by a brief overview of the few studies to date that have examined EI within a sport context.

EI as an important coaching ability. Take a moment to reflect back on an early youth athletic experience when you were genuinely engaged in the athletic learning and development process. Try to remember a time when you felt particularly connected to a coach. Most people would recollect memories of coaches who took the time to know them personally, provided an unconditional caring, and established a sense of team unity. They would tell stories of deep personal connection, unparalleled empathy, and enlightened self-understanding. They would talk about remarkable coaches who often seemed to know how to aptly push their motivational buttons more than the athlete knew how to themselves. Predictably, these reflections would lead to thoughts regarding the antitheses, memories of disconnections associated with frustration, misunderstanding, and role/expectation cluelessness. Thus, these stories can and should inform our understanding of the essential influence coaches have on the coach-athlete relationship and motivating their athletes. In addition, through these stories it should be easy to see that there is 
something more to the art of coaching than just knowing proper athletic technique and tactics. There are interpersonal skills that contribute to the art of coaching.

To date, the role EI plays in effective leadership has been well researched within business and teaching domains (Allen, J. \& Cohen, J., 2006; Palmer et al., 2000; Wong \& Law, 2002). In the 1940's, the Ohio State Leadership Studies suggested that leaders who are able to establish mutual trust, respect, and warmth and rapport with members of their group will be more effective. Leaders hold multiple roles and, as a result, need a range of skills to be effective, including the aforementioned critical interpersonal skills. However, little work has been done within a sport context that elucidates the role EI plays in athletic coaching effectiveness.

In a study conducted by Palmer et al. (2000), the relationship between EI and leadership was explored. EI was assessed by a modified version of the Trait Meta Mood Scale and leadership style was assessed with the Multifactor Leadership Questionnaire in 42 participants employed in management roles. Of the sample, 33 percent held higher management positions, 30 percent were middle level managers, and 27 percent held lower management positions (10 percent of subjects did not classify themselves falling within these categories). The MLQ is an accepted measure of leadership and defines leadership style as either Transformational (a leader who positively engages with others in such a way that the leader and follower raise one another to a higher level of motivation and morality) or Transactional (a leader who tries to exchange something of value, such as rewards contingent upon desired behaviors/performance). In most management domains, transformational leadership is considered a more effective leadership style and is consistently found to promote greater organizational performance (Palmer et al., 2000). The present study predicted that there would be a stronger correlation between EI and transformational leadership than between EI and transactional leadership. Results revealed that 
there were significant relationships between selected components of transactional leadership and EI sub-scales. Specifically, inspiration motivation and individualized consideration components of transformational leadership was significantly correlated with both the ability to monitor and manage emotions in oneself and others. Leaders who considered themselves as providing inspirational motivation to subordinates to work towards common goals reported they monitored and managed emotions both within themselves and others. Thus, the findings suggest that EI (measured by the ability to monitor and manage emotions within oneself and others) may be an important competency of transformational leadership.

It is important to note that these results should be approached with caution and are exploratory in nature. Furthermore, a shortcoming of this study is that it failed to assess the role of EI abilities outside of monitoring and managing emotions within oneself and others. Obviously this paints a limited picture of EI's role in leadership effectiveness. Palmer suggests that the EI's branch two abilities (i.e. the integration of emotions into thought to aid prioritization of thought) may contribute to creative thinking and flexible planning. To provide a more complete analysis of EI and leadership, the EI abilities of branch two needs to be investigated. Overall, these results require replication using a larger more diverse sample (look at leadership across different industries and private versus public sectors) before they should be interpreted without caution.

In several studies using college students, EI (specifically emotional regulation) was associated with several characteristics of positive social relations, even after personality and traditional intelligence were statistically controlled. Lopes and colleagues (2003) reported a significant positive correlation between the managing emotions branch of the MSCEIT and selfperceived quality of interpersonal relationships. In addition, in this same study MSCEIT scores 
were also associated with more supportive relationships with parents and less conflictual relationships with close friends.

Similarly, in a sample of 118 American college students, higher scores on the managing emotions subscale of the MSCEIT were positively related to the quality of interactions with friends, evaluated separately by participants and two friends (Lopes et al., 2004). In a diary study of social interaction with 103 German college students, managing emotions scores were positively related to the perceived quality of interactions with opposite sex individuals (Lopes et al., 2004). Scores on this subscale were also positively related to perceived success in social interactions with individuals of the opposite sex. In both studies, the main findings remained statistically significant after controlling for Big Five personality traits. Interestingly, the last two studies emphasized the importance of managing emotions as it relates to social interactions.

Brackett et al. (2003) measured the quality of interpersonal relationships by asking people to report the number of times they engaged in positive and negative behaviors with best friend, significant others, and parents. Positive relations were assessed with questions pertaining to behaviors such as having long conversations with friends and showing affection towards a significant other. Negative relations were assessed with questions pertaining to behaviors such as getting screamed at by a parent or drinking heavily with friends. These reports were correlated with EI scores. Results of this correlation analysis revealed that lower EI was associated with negative outcomes, including illegal deviant behavior and poor relations with friends. These findings remained significant even after scores on the Big Five and academic achievement were held constant. The significant correlation coefficients ranged between $\mathrm{r}=-.28$ to -.45 . Thus, with a sample size of 207 participants these results are not only significant but also meaningful. In another study, Cote et al. (2003) examined college student's interactions 
while working on a ten week group project. Students with high scores on the managing emotions subscale of the MSCEIT were more satisfied with other members, with the communication within the group, and with the social support they received from their group members. Interestingly, the last two studies not only emphasized the importance of EI, but also communication and feedback skills as important factors in positive social relationships. Thus, how EI influences communication skills might shed light on an important reason why coaches higher in EI may be more effective at developing strong relationship with athletes.

For example, for groups to obtain high levels of performance, particularly in team sports, group members, including coaches, need to communicate and work together effectively to achieve common goals. More specifically, communication in sport plays a key role in coaches and players effectively setting goals, identifying roles, providing evaluation/feedback, and building team cohesion. In order to communicate effectively, it is critical to be aware of your feelings and the feelings of the other group members and then act accordingly to prevent a loss of confidence in others, refusal to listen to others, and disruption of group chemistry (Whetten \& Cameron, 1991 as cited in Weinberg \& Gould, 2007). Accurately appraising emotions in others facilitates the use of emotional input into forming judgments and decision making. The accurate appraisal and then expression of emotions facilitates effectively communicating with others to meet their needs and accomplish their goals and objectives (George, 2000). Furthermore, research suggests that emotions, when properly managed and expressed, can drive trust, loyalty, and commitment (Fullam, 2002; Palmer et al., 2000). Thus, emotional awareness in self and others coupled with sensitivity (emotional regulation) in communication could play an important role in forming positive social relationships between teammates and coaches while simultaneously cultivating team cohesion. 
More specifically, the manner in which a coach communicates significantly influences how effectively a coach can get important information across to a player. For example, if athletes are faced with changes in expectations, roles, or playing time, they need accurate information from their coach about the impact of those changes. Often, the manner how a coach communicates this information can greatly influence how well this information will be received by players (i.e. will information be taken positively and used as motivation or taken negatively causing an athlete to become disgruntled). Coaches also need to have individual and group evaluation skills that enable them to observe athletic behaviors/skills and give accurate information to athletes on what they specifically need to do to improve. Effective communication skills that integrate emotional awareness in others are critical tools for enabling coaches to successfully complete these roles. These skills may include listening skills, expressive skills, and coach-player interaction management skills.

Although only a few studies have assessed EI and athletes (Jones, 2002, Zizzi et al., 2003; Perlini \& Halverson, 2006), even fewer have assessed EI and sport coaching. One of only two studies on EI and leadership within a sport domain that were found assessed the influence of leader efficacy and emotional intelligence on personal caring in physical activity (Magyar et al., 2007). In this study, 37 group leaders from a residential youth summer sports camp completed a questionnaire at the end of the 5-week camp. The questionnaire included a personal caring scale, a measure of emotional intelligence, and items assessing leader efficacy. This study hypothesized that EI plays in important factor in a leader's ability to effectively teach in a caring manner. Results of this study indicated a significant positive correlation between EI and personal caring. More specifically, regulation of emotions and leader efficacy emerged as significant and positive predictors of personal caring. The most influential emotional skill was the ability to 
regulate one's emotions (e.g., "I am able to control my temper and handle difficulties rationally"). The alpha coefficient of emotional regulation was $\alpha=.92$ and an $\alpha=.94$ for caring. There was a positive and significant correlation between emotional regulation and personal regulation of $r=.65, p<0.001$. This finding is notable because in order for leaders to establish caring relationships, they must be open, nonjudgmental, and fully receptive to the needs of their children. A potential shortcoming of this study is it used a newly designed 16 item measure of EI, the Wong Law Emotional Intelligence Scale (Wong \& Law, 2002). Although, Wong and Law's (2002) EI measure shows evidence of factor structure, internal consistency, convergence, and discriminate and incremental validity, no published third-party peer-reviewed analysis of this measure was found. Until this measure has been more frequently used in published/peerreviewed research and a more thorough analysis of the statistical validity and reliability is conducted by a third-party, these results should be interpreted with caution. Another shortcoming of this study is that campers' perceptions of a group leader's effectiveness and influence on positive development were unaccounted for. It would be a more complete study if the aforementioned information was collected as a check against self-report biases and also to correlate with caring and EI data.

Regardless, this study highlights that the interaction of leaders with other individuals is an important determinant of leadership effectiveness. Thus within a sport context, because coach-athlete and athlete-athlete interpersonal interactions exist, emotional awareness and regulation are important factors that can influence the quality of these interactions. Furthermore, the ability to empathize, display optimism, motivate, and build morale are key components that can be linked to EI and are determinants of effective leadership (Caruso et al., 2004). Given that the aforementioned literature establishes a relationship between children's perceptions of a 
caring environment and subsequent positive developmental outcomes, it would be important to assess pertinent characteristics within coaches that influence their ability to care. Overall, efforts invested on researching EI's role in coaching has the potential to lead to significant advancements to coaching effectiveness literature. Knowledge gained from research on EI and coaching may provide a better understanding of coaching effectiveness and help produce valuable tools for training and development of coaches that could lead to the enhancement of team climate and performance.

The only other study that has assessed the relationship between EI and coaching effectiveness has been published within the last year. Thelwell, Lane, Weston, \& Greenlees (2008) examined the relationship between emotional intelligence and coaching efficacy using the Emotional using Intelligence Scale and the Coaching Efficacy Scale. A total of 99 coaches were each given the EIS and CES (with subscales motivation; game strategy; technique; character building). One key finding was that both the coach appraisals of their own emotions and regulation of emotions were significantly correlated with all CES subscales. A second key finding was the significant correlation between the CES subscales and the coaches' ability to appraise the emotions of others. Although these correlations were significant, they provided only weak to moderate relationships and selection of coaches for the research sample was very liberal with coaches from 13 different sports represented and coaches from 2 to 30 years of coaching experience allowed to participate. Thus, this was a decent first attempt to assess the relationship between EI and coaching effectiveness, but more research is needed.

In summary, emotional intelligence has been positively correlated with empathy (e.g., perceived emotional response to others and concern about the feeling of others; Mayer, Caruso, \& Salovey, 1999). Similarly, research suggests a coach's EI may play a critical role in a coach's 
ability to effectively communication with athletes. As mentioned previously, EI may influence a leader's ability to effectively teach in a caring manner (Magyar et al., 2007) and a coach's ability to motivate their players (Thelwell, et al., 2008).

Recognizing and appropriately responding to follower's emotions is necessary for leaders to develop high quality interpersonal relationships (Salovey \& Mayer, 1990). Thus, the strength of a relationship between a coach and athlete could hinge on a coach's EI. In addition, since emotional intelligence has been linked to a leaders ability to motivated followers, a coach's EI may also influence the how effectively s/he can motivate an athlete.

\section{Summary of the review of literature}

The effect a coach has on his/her athletes is a phenomenon that has been studied for the last several decades when researchers in the early 70's began to recognize the potential impact of youth coaches on their athletes. This research has supported the claim that coaches and the quality of the coach-athlete relationship have a direct impact on many psychosocial variables of athletes, such as satisfaction, self-confidence, and motivation. Interestingly, these research findings within sport coaching overlap with numerous findings from more established research centered on leadership effectiveness within business and healthcare fields. However, emotional intelligence, a new and popular construct within corporate and healthcare research, has yet to permeate into sport coaching research. With that said, research within non-sport fields has linked EI to the ability to empathize, display optimism, motivate, and build morale which are key determinants of effective leadership (Caruso et al., 2004). These results seem highly relevant to coaching and reveal a current gap in sport coaching research.

Although EI has not yet been incorporated into the sport coaching domain, there are other accepted constructs that have traditionally been employed to evaluate and assess a coach's ability 
to impact player emotions and efforts. Motivational climate and coach athlete relationships are integral components of a coach's success. For example, motivational climate affects player outcomes that range from attitude toward winning (Ntoumanis \& Biddle, 1999) to the quality of relationships among teammates and coaches (Fry \& Newton, 2003). Similarly, a good coach athlete relationship has been correlated with variables that range from general satisfaction and positive emotions to a positive experience by athlete and coach (Bortoli et al., 1995). In assessing such accepted constructs in relation to EI, one may be able to gain a base understanding of how EI can be further analyzed in sport, and how a coach's level of EI may affect the coach athlete relationship and team motivational climate. The proposed study may help determine the relationships that may exist between the constructs of EI, coach-athlete relationships, and team motivational climate.

In summary, this study has the potential to fill the current gap in leadership literature and determines if research efforts on emotional intelligence and coaching may reap important sport specific findings that will help answer what it takes to be a successful coach. The new construct of emotional intelligence may provide important insight into why this process comes easier to some and not others. Lastly, EI may be a critical coaching ability that when used effectively allows a coach to become more in tune with the unique emotional, motivational, relationship needs of an athlete. 


\section{APPENDIX I}

REVIEW OF LITERATURE REFERENCES 


\section{REVIEW OF LITERATURE REFERENCES}

Allen, J., \& Cohen, J. (2006). Emotional intelligence in classrooms and in schools: What we see in the educational setting In K. Murphy (Ed.), A critique of emotional intelligence: What are the problems and how can they be fixed? (pp. 125-139). Mahwah, New Jersey LEA.

Allen, J.B., \& Howe, B.L. (1998). Player ability, coach feedback, and female adolescent athletes' perceived competence and satisfaction. Journal of Sport \& Exercise Psychology,20, 280299.

Ames, C., \& Archer, J. (1988). Achievement goals in the classroom: Students' learning strategies and motivation processes. Journal of Educational Psychology, 80, 260-267.

Balaguer, I., Crespo, M., \& Duda, J. L., (1996). The relationship of motivational climate and athletes' goal orientation to perceived/preferred leadership style. Journal of Sport and Exercise Psychology, 18, 13.

Bortoli, L., Robazza, C., \& Giabardo, S. (1995). Young athletes’ perception of coaches' behavior. Perceptual and Motor Skills, 81, 1217-1218.

Brackett, M. A., \& Mayer, J. D. (2003). Convergent, Discriminant, and Incremental Validity of Competing Measures of Emotional Intelligence. Personality and Social Psychology Bulletin, 29(9), 1147.

Brackett, M. A., \& Salovey, P. (2006). Measuring emotional intelligence with the MayerSalovey-Caruso Emotional Intelligence Test (MSCEIT). Psicothema, 18, 34-41.

Caruso, D. R., \& Wolfe, C. J. (2004). Emotional intelligence and leadership development. In D. V. Day, S. J. Zaccaro and S. M. Halpin (Eds.), Leader development for transforming organizations: Growing leaders for tomorrow. (pp. 237-263). Mahwah, NJ, US:

Lawrence Erlbaum Associates Publishers. 
Chelladurai, P., \& Saleh, S.D. (1978). Preferred leadership in sports. Canadian Journal of Applied Sport Sciences, 3, 85-92.

Chelladurai, P., \& Saleh, S. D. (1980). Dimensions of leader behavior in sports: Development of a leadership scale. Journal of Sport Psychology, 2, 34-45.

Clews, G. J., \& Gross, J. B. (1995). Individual and social motivation in Australian sport. In Sport psychology: Theory, applications and issues. (pp. 90-121). Brisbane, Australia: John Wiley.

Conte, J.M. (2005). A review and critique of emotional intelligence measures. Journal of Organizational Behavior, 26, 433-440.

Duda, J. L. \& Chi, L. (1989,September). The effect of task and ego-involving conditions on perceived competence and causal attributions in basketball. Paper presented at the meeting of the Association for the Advancement of Applied Sport Psychology, University of Washington, Seattle, WA.

Fox, L.D., Rejeski, W.J., \& Gauvin, L. (2000). Effects of leadership style and group dynamics on enjoyment of physical activity. American Journal of Health Promotion, 14, 277-283.

Fry, M., \& Newton, M. (2003). Application of achievement goal theory in an urban youth tennis setting. Journal of Applied Sport Psychology, 15(1), 50-66.

Fullam, A. (2002). Adult attachment, emotional intelligence, health, and immunological responsiveness to stress. Unpublished dissertation, Rutgers University.

Gardner, H. (1983). Frames of mind: The theory of multiple intelligences. New York: Basic Books.

George, J. M. (2000). Emotions and leadership: The role of emotional intelligence. Human Relations, 53(8), 1027-1055. 
Goleman, D., Boyatzis, R. E., \& McKee, A. (2002). Primal leadership: Realizing the power of emotional intelligence. Boston, MA: Harvard Business School Press.

Gould, D., Guinan, D., Greenleaf, C., Medbery, R., \& Peterson, K. (1999). Factors affecting Olympic performance: Perceptions of athletes and coaches from more and less successful teams. The Sport Psychologist, 13(4), 371-394.

Hardy, L. (1997). The Coleman Roberts Griffith Address: Three myths about applied consultancy work. Journal of Applied Sport Psychology, 9, 277-294.

Heuzé, J. P., Sarrazin, P., Masiero, M., Raimbault, N., \& Thomas, J. P. (2006). The relationships of perceived motivational climate to cohesion and collective efficacy in elite remale teams. Journal of Applied Sport Psychology, 18(3), 201-218.

Hoigaard, R., \& Jorgensen, A. (2007). Coaching conversations - A way of fostering athletes to peak performance. USOC Olympic Coach E-Magazine, 19.

Janssen, J., \& Dale, G. A. (2002). The seven secrets of successful coaches: How to unlock and unleash your team's full potential. Tucson, AZ: Winning the Mental Game.

Jones, G. (2002). Performance excellence: A personal perspective on the link between sport and business. Journal of Applied Sport Psychology, 14, 268-281.

Jowett, S. (2003). When the honeymoon is over: A case study of a coach-athlete relationship in crisis. Sport Psychologist, 17, 444-460.

Jowett, S. (2005). On repairing and enhancing the coach-athlete relationship. In S. Jowett \& M. Jones (Eds.), Psychology of sport coaching (pp. 14-26). Leicester: The British Psychological Society. 
Jowett. S. (2007). Interdependence Analyisis and the 3+1Cs in the Coach-Athlete Relationship. In S. Jowett \& D. Lavallee (Eds.), Social Psychology in Sport (pp. 15-27). Human Kinetics, IL: Champaign.

Jowett, S., \& Cockerill, I. M. (2002). Incompatibility in the coach-athlete relationship. In I. M. Cockerill (Ed.), Solutions in sport psychology (pp. 16-31). London: Thomson Learning.

Jowett, S., \& Cockerill, I. M. (2003). Olympic Medalists' perspective of the athlete-coach relationship. Psychology of Sport and Exercise, 4, 313-331.

Jowett, S. \& Meek, G. A. (2000). The coach-athlete relationship in married couples: an exploratory content analysis. The Sport Psychologist, 14, 157 - 175.

Jowett, S., \& Ntoumanis, N. (2004). The coach-athlete relationship questionnaire (CART-Q): development and initial validation. Scandinavian Journal of Medicine and Science in Sports, 14(4), 245-257.

Kelley H.H., Berscheid E., Christensen A., Harvey J.H., Huston T.L., Levinger G., McClintock E., Peplau L.A., Peterson D.R., (Eds.). (1983). Close Relationships. New York: Freeman. Kramer, E. (1967). A contribution toward the validation of the FIRO-B Questionnaire. Journal of Projective Techniques and Personality Assessment, 31, 80-81

Lopes, P.N., Brackett, M., Nezlek, J., Schutz, A., Sellin, I., \& Salovey, P. (2004). Emotional Intelligence and Social Interaction. Personality and Social Psychology Bulletin. 30. 10181034.

Lopes, P.N., Salovey, P., \& Straus, R. (2003) Emotional intelligence, personality and the perceived quality of social relationships. Personality and Individual Differences, 3,641659. 
Martin, S.B., Dale, G.A., \& Jackson, A.W. (2001). Youth coaching preferences of adolescent athletes and their parents. Journal of Sport Behavior, 24 (2), 196-215.

Mayer, J. D., Caruso, D. R., \& Salovey, P. (1999). Emotional intelligence meets traditional standards for an intelligence. Intelligence, 27(4), 267-298.

Mayer, J. D., \& Salovey, P. (1997). What is emotional intelligence? In P. Salovery, and D. Sluyteri (Ed.), Emotional development and emotional intelligence: Implications for educators (pp. 3-31). New York: Basic Books.

Mayer, J. D., Salovey, P., \& Caruso, D. R. (2002). Mayer-Salovey-Caruso Emotional Intelligence Test (MSCEIT): user's manual. Toronto: Multi-Health Systems.

Mayer, J. D., Salovey, P., Caruso, D. R., \& Sitarenios, G. (2003). Measuring emotional intelligence with the MSCEIT V2. 0. Emotion, 3(1), 97-105.

McCallister, S.G., Blinde, E., \& Weiss, W.M. (2000). Teaching values and implementing philosophies: dilemmas of the youth sport coach. Physical Educator, 57, 33-45.

McCann, S. (1999). Emotional intelligence: the secret of athletic excellence. Olympic Coach, $9(2), 8-9$.

Meyer, B. B., \& Fletcher, T. B. (2007). Emotional intelligence: A theoretical overview and implications for research and professional practice in sport psychology. Journal of Applied Sport Psychology, 19, 1-15.

Meyer, B. B., and Zizzi, S. (2007). Emotional intelligence in sport: Conceptual, methodological, and applied issues. In A.M. Lane (ed.), Mood and human performance: Conceptual, measurement, and applied issues (pp. 131-154). Hauppauge, NY: Nova Science.

Miller, S. \& Weinberg, R. (1991). Perceptions of psychological momentum and their relationship to performance. Sport Psychologist, 5, 211-222. 
Newton, M., Duda, J. L., \& Yin, Z. (2000). Examination of the psychometric properties of the Perceived Motivational Climate in Sport Questionnaire-2 in a sample of female athletes. Journal of Sports Sciences, 18, 275-290.

Nicholls, J. G. (1984). Achievement motivation: Conceptions of ability, subjective experience, task choice, and performance. Psychological Review, 91, 328-34.

Nicholls, J. G. (1989). The competitive ethos and democratic education. Cambridge, MA: Harvard University Press.

Ntoumanis, N., \& Biddle, S. J. H. (1999). A review of motivational climate in physical activity. Journal of Sports Sciences, 17(8), 643-665.

Palmer, B.,Walls, M., Burgess, Z., \& Stough, C. (2000). Emotional intelligence and effective leadership. Leadership and Organizational Development Journal, 22, 5-10.

Pau, A. \& Croucher, R. (2003). Emotional intelligence and perceived stress in dental undergraduates. Journal of Dental Education, 67, 9, 1023-1028.

Pensgaard, A. M., \& Roberts, G. C. (2002). Elite athletes' experiences of the motivational climate: The coach matters. Scandinavian Journal of Medicine and Science in Sports, $12(1), 54-59$.

Perlini, A. H., \& Halverson, T. R. (2006). Emotional intelligence in the National Hockey League. Canadian Journal of Behavioral Science, 38(2), 109-120.

Reinboth, M., \& Duda, J. L. (2006). Perceived motivational climate, need satisfaction and indices of well-being in team sports: A longitudinal perspective. Psychology of Sport \& Exercise, 7(3), 269-286. 
Roberts, G. C., Treasure, D. C., \& Kavussanu, M. (1997). Motivation in physical activity contexts: An achievement goal perspective. Advances in motivation and achievement, 10, $413-447$.

Salovey, P., \& Mayer, J. D. (1990). Emotional intelligence. Imagination, Cognition and Personality, 9, 185-211.

Scanlan, T.K., \& Lewthwaite, R. (1986). Social psychological aspects of competition for male youth sport participants: IV. Predictors of enjoyment. Journal of Sport Psychology, 8, 2535.

Schliesman, E.S. (1987). Relationship between the congruence of preferred and actual leader behavior subordinate satisfaction with leadership. Journal of Sport Behavior, 10, 157166.

Seifriz, J.J., Duda, J.L. and Chi, L. (1992). The relationship of perceived motivational climate to intrinsic motivation and beliefs about success in basketball. Journal of Sport and Exercise Psychology, 14, 375-391.

Shaw, J.M., Dzewaltowski, D.A., \& McElroy, M. (1992). Self-efficacy and causal attributions as mediators of perceptions of psychological momentum. Journal of Sport \& Exercise Psychology, 14, 134-147.

Smith, R. E., \& Smoll, F. L., (1990). Self-esteem and children's reactions to youths: A filed study of self-enhancement processes. Developmental Psychology, 26, 987-993.

Smith, R.E., \& Smoll, F.L. (1991). Behavioral research and intervention in youth sports. Behavior Therapy, 22, 329-344. 
Smith, R. E., Smoll, F. L., \& Curtis, B. (1979). Coach effectiveness training: A cognitivebehavioral approach to enhancing relationship skills in youth sport coaches. Journal of Sport Psychology, 1(1), 59-75.

Sternberg, R. J., Forsythe, G. B., Hedlund, J., Horvath, J. A., Wagner, R. K., Williams, W. M., Snook, S. A., \& Grigorenko, E. L. (2000). Practical intelligence in everyday life. New York: Cambridge.

Theeboom, M., De Knop, P. and Weiss, M.R. (1995). Motivational climate, psychological response, and motor skill development in children's sport: A Weld-based intervention study. Journal of Sport and Exercise Psychology, 17, 294-311.

Thelwell, R., Lane, A., Weston, N., \& Greenlees, L. (2008). Examining relationships between emotional intelligence and coaching efficacy. International Journal of Sport \& Exercise Psychology, 6(2), 224-235.

Vealey, R. (2001). Understanding and enhancing self-confidence in athletes. In R. Singer, H. Hausenblas, and C. Janelle (Eds.), Handbook of sport psychology (2nd ed., pp. 550-565). New York: Wiley.

Walling, M.D., Duda, J.L. and Chi, L. (1993). The Perceived Motivational Climate in Sport Questionnaire: Construct and predictive validity. Journal of Sport and Exercise Psychology, 15, 172-183.

Weinberg, R., \& Gould, D. (2007). Foundations of sport and exercise psychology (4 ed.). Champaign, IL: Human Kinetics.

Weinberg, R., \& McDermott, M. (2002). A comparative analysis of sport and business organizations: Factors perceived critical for organizational success. Journal of Applied Sport Psychology, 14(4), 282-298. 
Weinberg, R.S., Yukelson, D., \& Jackson, A. (1980). Effects of public verses private efficacy expectations on competitive performance. Journal of Sport Psychology, 2, 340-349.

Whitehead, J., Andree, K. V., \& Lee, M. J. (1997). Longitudinal interactions between dispositional and situational goals, perceived ability, and intrinsic motivation. Innovations in sport psychology: Linking theory and practice. Proceedings of the IX World Congress in Sport Psychology: Part II, 750-752.

Wong, C.S., \& Law, K. S. (2002). The effects of leader and follower emotional intelligence on performance and attitude: An exploratory study The Leadership Quarterly, 13(3), 243274.

Wylleman, P. (2000). Interpersonal relationships in sport: Uncharted territory in sport psychology research. International Journal of Sport Psychology, 31, 555-572.

Wylleman, P., De Knop, P., Vanden Auweele, Y., \& Sloore, H. (1994). The development of a questionnaire to assess elite young athletes' perceptions of the parents-coach relationship. Congres International De La Societe Francaise De Psychologie Du Sport, 79-80.

Wylleman, P., De Knop, P., Vanden Auweele, Y., \& Sloore, H. (1997). The athletic triangle in competitive youth sports: Young athletes' perceptions of the athlete-coach-parents relationships. Proceedings of the World Congress of Sport Psychology, Israel, 762-764.

Zizzi, S. J., Deaner, H. R., \& Hirschhorn, D. K. (2003). The relationship between emotional intelligence and performance among college baseball players. Journal of Applied Sport Psychology, 15(3), 262-269. 